\title{
The Combustion Kinetics of the Lignocellulosic Biofuel, Ethyl Levulinate
}

\author{
Manik Kumer Ghosh ${ }^{\mathrm{a}, \mathrm{b}^{*}}$, Mícheál Séamus Howard ${ }^{\mathrm{a}, \mathrm{b}}$, Yingjia Zhang ${ }^{\mathrm{c}}$, Khalil Djebbi ${ }^{\mathrm{d}}$, Gianluca \\ Capriolo $^{\mathrm{b}}$, Aamir Farooq ${ }^{\mathrm{d}}$, Henry J. Curran ${ }^{\mathrm{c}}$, Stephen Dooley ${ }^{\mathrm{a}, \mathrm{b}^{*}}$

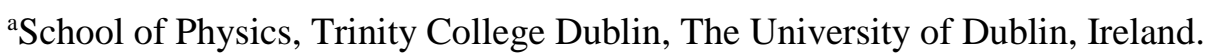 \\ ${ }^{b}$ Department of Chemical Sciences, University of Limerick, Ireland. \\ ${ }^{\mathrm{c}}$ Combustion Chemistry Centre, National University of Ireland, Galway, Ireland. \\ ${ }^{\mathrm{d}}$ Clean Combustion Research Center, King Abdullah University of Science and Technology, Thuwal, \\ Saudi Arabia.
}

*Corresponding author:

Manik Kumer Ghosh: ghoshm@tcd.ie

\begin{abstract}
Ethyl levulinate (Ethyl 4-oxopentanoate) is a liquid molecule at ambient temperature, comprising of ketone and ethyl ester functionalities and is one of the prominent liquid fuel candidates that may be easily obtained from lignocellulosic biomass. The combustion kinetics of ethyl levulinate have been investigated. Shock tube and rapid compression machine apparatuses are utilised to acquire gas phase ignition delay measurements of $0.5 \%$ ethyl levulinate $/ \mathrm{O}_{2}$ mixtures at $\phi=1.0$ and $\phi=0.5$ at $\sim 10$ atm over the temperature range $1000-1400 \mathrm{~K}$. Ethyl levulinate is observed not to ignite at temperatures lower than $\sim 1040 \mathrm{~K}$ in the rapid compression machine. The shock tube and rapid compression machine data are closely consistent and show ethyl levulinate ignition delay to exhibit an Arrhenius dependence to temperature. These measurements are explained by the construction and analysis of a detailed chemical kinetic model. The kinetic model is completed by establishing thermochemical-kinetic analogies to 2-butanone, for the ethyl levulinate ketone functionality, and to ethyl propanoate for the ethyl ester functionality. The so constructed model is observed to describe the shock tube data very accurately, but computes the rapid compression machine data set to a lesser but still applicable fidelity. Analysis of the model suggests the autooxidation mechanism of ethyl levulinate to be entirely dominated by the propensity for the ethyl ester functionality to unimolecularly decompose to form levulinic acid and ethylene. The subsequent reaction kinetics of these species is shown to dictate the overall rate of the global combustion reaction. This model is then
\end{abstract}


use to estimate the Research and Motored Octane Numbers of ethyl levulinate to be $\geq 97.7$ and $\geq 93$, respectively. With this analysis ethyl levulinate would be best suited as a gasoline fuel component, rather than with diesel as suggested by the literature. Indeed it may be considered to be useful as an octane booster. The ethyl levulinate kinetic model is constructed within a state-of-the-art gasoline surrogate combustion kinetic model and is thus available as a tool with which to investigate the use of ethyl levulinate as a gasoline additive.

Keywords: Ethyl levulinate, lignocellulosic biofuel, kinetic model, ignition delay, gasoline. 


\section{Introduction}

The catalytic conversion of biomass derived cellulose, hemicellulose and lignin to platform chemicals and fuels has been widely recognised as an opportunity to produce sustainable economies. Ethyl levulinate (EL) (Figure 1) is one of many liquid phase molecules that may be easily produced by the acid hydrolysis of cellulose. It may be produced at the high yields that are essential for potential economic viability, either by reaction of ethanol (the biorefinery platform chemical) and levulinic acid, or by the insitu acid-catalysed reaction of cellulosic sugars with ethanol [1]. The synthetic processes that produce ethyl levulinate from cellulose use ethanol (both as a solvent and reacting partner) as a means of functionalising the levulinic acid precursor [2]. This alkylation also improves the energy density of the cellulose derived functionalities, and their solubility in conventional petroleum derived liquid hydrocarbon fuels. One can also think of the cellulose as improving the fuel properties of Ethanol, notably the energy density. Ethyl levulinate has an energy density of $31.2 \mathrm{MJ} / \mathrm{L}$ (energy density of gasoline is $44.4 \mathrm{MJ} / \mathrm{kg}$ ), much superior to that of ethanol (24 MJ/L). The sustainability benefits of co-reacting cellulose with ethanol are obvious when one realises that $71 \%$ of the ethyl levulinate carbon, and $58 \%$ of the ethyl levulinate hydrogen are contributed by the cellulose. 
Ethyl levulinate
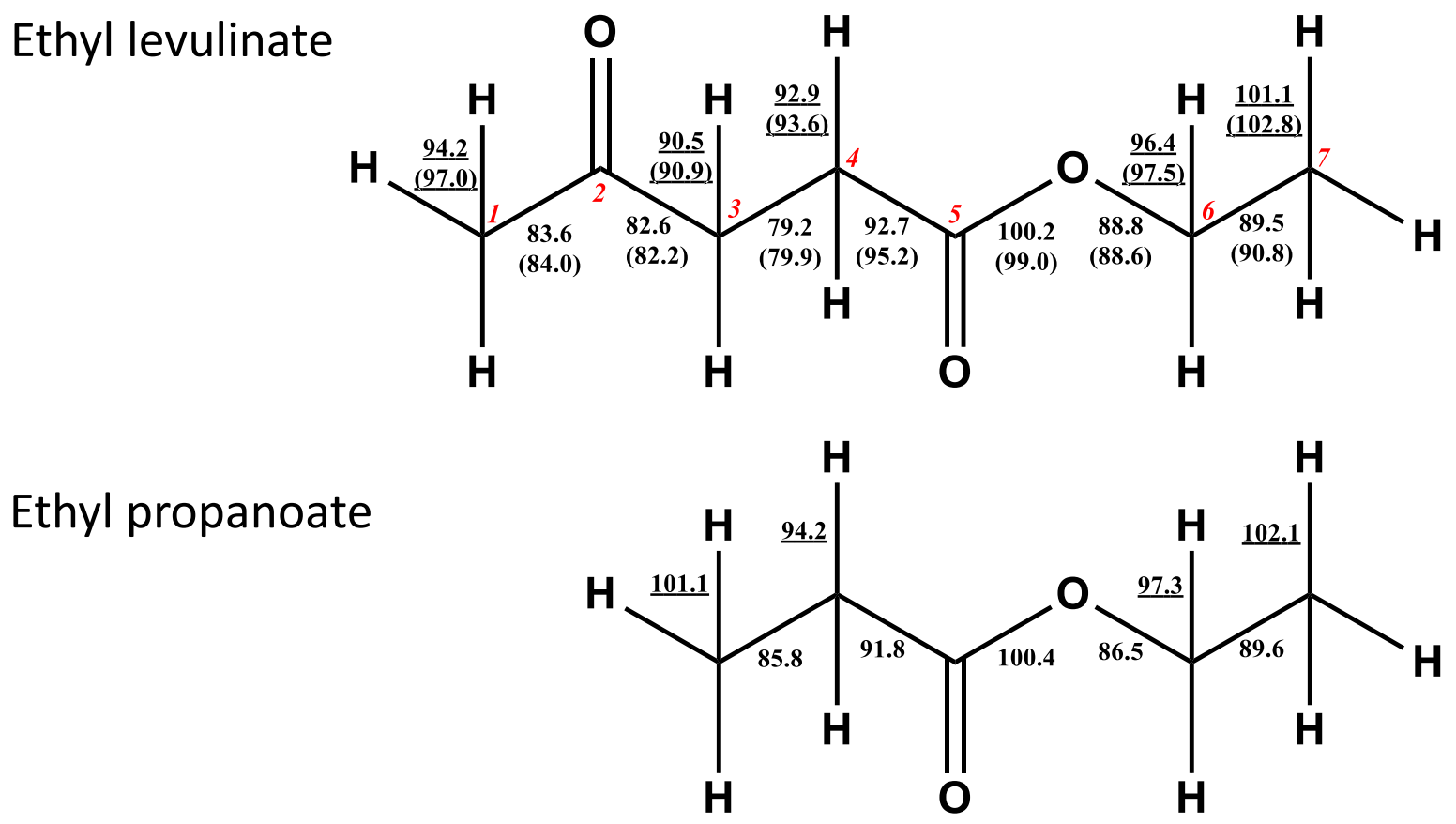

\section{2-butanone}

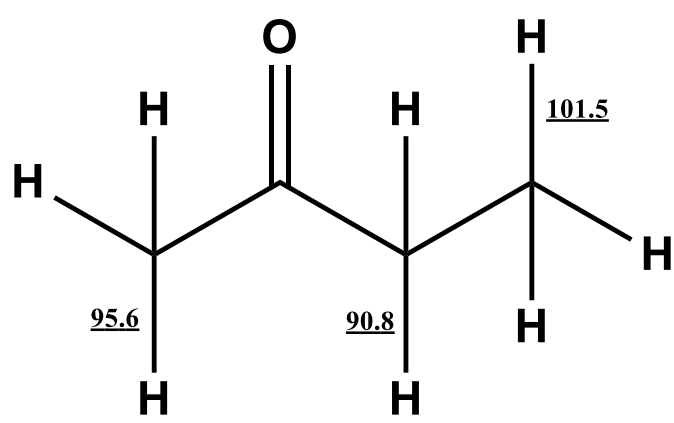

Figure 1. Chemical structures and bond dissociation energies (kcal/mol) of ethyl Levulinate. Carbonhydrogen bond dissociation energies are underlined. Values without parentheses are average of data produced by isodesmic work reactions calculated at CBS-QB3, CBS APNO and G4MP2 levels of theory [3]. Values in parentheses are group additivity estimates. Ethyl propanoate from [4] and 2butanone from [5].

Ethyl levulinate (EL) has a high flash point of $90{ }^{\circ} \mathrm{C}$, attributable to its low volatility as prescribed by a boiling point of $206^{\circ} \mathrm{C}$. Due to its high oxygen content and high boiling point, ethyl levulinate has been originally espoused as a suitable oxygenate additive for diesel fuels to reduce soot formation. Lei et al. [6], have reported successful engine tests of various blends of ethyl levulinate, and ethyl levulinate/n-butanol with a diesel fuel, showing marginal increases in brake specific fuel consumption and also marginal effect on the emission of unburned hydrocarbons for 10 vol\% ethyl 
levulinate mixtures with a road diesel. Koivistos et al. [7], in a direct injection compression ignition engine, studied a series of oxygenated fuel components both as neat fuels, and as $30 \mathrm{vol} \%$ blends with n-heptane. They noted a reduction in overall particulate mass when using ethyl levulinate as a fuel component, but also noted an increase in the overall number of particulate particles. Windom et al. [8] have determined the volatility behaviour of (1-20 vol\%) ethyl levulinate blends with Ultra Low Sulphur Diesel (ULSD) and with biodiesel. They show that, while ethyl levulinate is more volatile than either fuel, modest additions of ethyl levulinate to diesel will not significantly affect the overall volatility of the fuel.

The majority of existing literature proposes the use of ethyl levulinate as a sustainable blendstock for use with diesel fuel, however, the combustion reactivity of ethyl levulinate may present itself as a limiting factor in this regard. Koivistos et al. [7] reported that ethyl levulinate does not ignite at the typical configuration of a tested diesel engine, also noting that ethyl levulinate/n-heptane mixtures showed the longest ignition delays of a large series of fuels tested. Similarly, Murphy et al. [9] corroborate this reactivity indicator when quoting a Derived Cetane Number for ethyl levulinate of "< 5", as deduced by an ignition quality tester. Christensen et al. [10] note that this low cetane number will limit the quantity of ethyl levulinate that might be blended with diesel fuel. The miscibility of ethyl levulinate may also be another constraining factor. Christenson et al. [10] purposely investigated the miscibility of ethyl levulinate with conventional Ultra-Low Sulphur Diesel (ULSD) showing the addition of $10 \mathrm{vol} \%$ ethyl levulinate to result in a significantly higher cloud point in comparison to unblended diesel. Moreover, in the range of $-10{ }^{\circ} \mathrm{C}$ to $+10{ }^{\circ} \mathrm{C}$, Christensen et al. [10] report a propensity for a significant fraction of ethyl levulinate to phase separate from the blended diesel. They indicate that this may lead to operational difficulties in vehicle fuel storage tanks and with engine fuel injectors under cold operating conditions. However, both Lake and Burton [11] and Joshi et al. [12] show that such miscibility restrictions are less confining when using biodiesel as the blend component, or as a co-solvent for ethyl levulinate with conventional ultra-low sulphur diesel. 
The low cetane number and reactivity of ethyl levulinate may favour its use as a gasoline additive. It is also important to note that ethyl levulinate appears to be more miscible in tested gasolines than the diesels. Christensen et al. [13] show that at 10 vol\% ethyl levulinate did not separate from the gasoline until $-40{ }^{\circ} \mathrm{C}$. Christensen et al. [13] also noted that the use of ethyl levulinate (at $3.7 \mathrm{wt} \%$ oxygen, $\sim 5.9 \mathrm{~mol} \%$ ethyl levulinate) as a gasoline extender gives favourable attributes over other possible oxygenated additives, including ethanol and propanols, by; lowering the volatility of the fuel; increasing blended octane numbers by $\sim 15$. Similarly, Tian et al. [14] found in both engine and ignition quality tests that ethyl levulinate has a higher anti knock propensity than EURO95 gasoline ( $\mathrm{RON}=95)$. This further suggests that ethyl levulinate would be better placed as a gasoline additive. Tian et al., through analogy to ethyl butanoate, espouse that the ethyl levulinate combustion kinetics is dominated by the decomposition pathway to ethylene and levulinic acid, which results in the low reactivity of the molecule. However, a detailed study on the reaction kinetics of ethyl levulinate is needed to test this theory.

The position of the fuel and combustion literature on the prospective uses of ethyl levulinate may thus be summarised as suggesting ethyl levulinate to be intermediate in physical property between gasoline and diesel distillate, but of a kinetic reactivity much lower than conventional diesel, and even lower than conventional gasoline. We note that the to-date reactivity indicators are all derived from engine like configurations, where no information of a fundamental kinetic nature is available for reference. This study aims to scientifically resolve the combustion kinetics of ethyl levulinate and their interaction with gasoline combustion kinetics. To achieve this the current study:

1) Determines the first entirely gas phase measurements of ethyl levulinate combustion kinetics by the measurement of ignition delay times. 
2) Proposes and tests a detailed combustion kinetic model to describe ethyl levulinate and ethyl levulinate/gasoline combustion, and uses this model to make predictions of the octane numbers of ethyl levulinate and ethyl Levulinate/gasoline mixtures.

\section{Experimental}

Ignition delay times were measured with the Rapid Compression Machine (RCM) Facility at National University of Ireland, Galway and the High Pressure Shock Tube (HPST) facility at King Abdullah University of Science and Technology (KAUST).

The inclusion of three oxygen atoms in the ethyl levulinate molecular structure produces a low vapour pressure of $0.17 \mathrm{mbar}$ at $298 \mathrm{~K}$. The substance is thus difficult to configure gas phase measurements for. As a result, the parameter space of mixture fraction and pressure that the experimental devices of this study can reliably access for the case of ethyl levulinate is constrained. Out of necessity to regulate the ethyl levulinate vapour pressure in the compressed volume of the RCM to be lower than the saturation vapour pressure at the initial operating temperature (348-398 K) of that device by factor of 5 , the ethyl levulinate fraction has been restricted to $0.5 \%$, also restricting the compressed pressures safely achievable to $\sim 10$ atm. To parameterise the effect of oxygen concentration, ethyl levulinate:oxygen equivalence ratios of 1.0 and 0.5 are selected. For consistency the shock tube examines the same mixture fractions as the RCM study. Experimental details specific to each device follow below.

The twin-opposed piston RCM is a clone of the original NUI Galway (Shell-Thornton) device which produces compression times of approximately $16 \mathrm{~ms}$. Creviced piston heads are used to suppress the formation of vortices within the boundary layer gases, minimizing the effects of temperature inhomogeneities on the intended adiabatic core gas [15]. In this study the narrow range of compressed gas temperatures required to observe the full extent of ethyl levulinate reactivity are achieved by employing a compression ratio of $\sim 13: 1, \mathrm{~N}_{2} /$ Ar diluent compositions of 65/35 and 40/60 
mol\%, with initial temperatures in the range of 343-393 K. A full accounting of the experimental conditions is provided in Table 1 . The ethyl levulinate test fuel $(99.85 \%)$ is supplied by SigmaAldrich Ireland Ltd, while nitrogen (99.95\%), oxygen (99.5\%) and argon (99.995\%) are supplied by BOC Ireland Ltd. Batch mixtures are manometrically prepared in $80{ }^{\circ} \mathrm{C}$ mixing tanks twelve hours before conducting experiments.

The reaction chamber allows for variation of the initial temperature. A gas handling manifold is also heated and its temperatures monitored to keep the reactant mixtures above the saturation temperature of ethyl levulinate at the corresponding compressed pressure at all times. The pressure history inside the reaction chamber is measured using a pressure transducer (Kistler 603B) and a charge amplifier (Kistler 5018). Both the pressure and piston position signals are recorded by a digital oscilloscope (PicoScope 4424). The non-linearity of the pressure transducer is less than $\pm 1 \%$ of the full scale output. The compression pressure was held at 10 atm to within $3 \%$ for all of the experiments presented, see Table 1. A photomultiplier detector (Hamamastu 166) was used to record the emission of light and the measured ignition delay times are reproducible to $\pm 15 \%$.

As the RCM environment is characterised by heat losses [15], the compressed temperature is determined from the measurement of the compressed pressure by the isentropic relationship; $\ln \left(\frac{p_{c}}{p_{i}}\right)=\int_{T_{i}}^{T_{c}} \frac{\gamma}{\gamma-1} \frac{d T}{T}$, where $\gamma$ is the compressibility of the test gas; the compressed pressure, $p_{c}$; the initial pressure, $p_{i}$; the compressed temperature, $T_{\mathrm{c}}$; and the initial temperature; $T_{i}$. Non-reactive experiments are performed to account for the dynamic effect of heat losses, allowing the temperature history experienced to be approximated in zero dimensional simulations of the RCM ignition experiments. The non-reactive measurements replace oxygen with the inert, nitrogen, which has a similar compressibility value of $\gamma$. Typical reactive and accompanying non-reactive pressure and emission histories are shown in Figure 2. Considering the weak ignition energy release events 
(discussed below) for these dilute mixtures, the ignition delay time was defined as the time from the end of compression to the subsequent peak of light emission, see Figure 2.

The experimental uncertainty is $\pm 10 \mathrm{~K}$ in reported temperatures, $\pm 0.1 \mathrm{~atm}$ in reported pressures, $\pm 15 \%$ in reported ignition delay times and $<1 \%$ (relative) in reported mixture fractions.

\begin{tabular}{|c|c|c|c|c|c|}
\hline $\begin{array}{c}\text { Initial } \\
\text { Pressure /atm }\end{array}$ & $\begin{array}{c}\text { Initial Temperature } \\
\text { / K }\end{array}$ & $\begin{array}{l}\text { Compressed } \\
\text { Pressure / atm }\end{array}$ & & $\begin{array}{l}\text { mpressed } \\
\text { erature / K }\end{array}$ & $\begin{array}{c}\text { Ignition } \\
\text { Delay } \\
\text { Time / ms }\end{array}$ \\
\hline \multicolumn{6}{|c|}{$\mathrm{EL} / \mathrm{O}_{2} / \mathrm{N}_{2} / \mathrm{Ar}, \quad 0.005 / 0.0425 / 0.6185 / 0.334$} \\
\hline$* 0.240$ & 348 & 10.16 & & 1130 & 2.00 \\
\hline$* 0.240$ & 348 & 10.14 & & 1129 & 1.98 \\
\hline 0.264 & 388 & 9.79 & & 1098 & 8.55 \\
\hline 0.264 & 388 & 9.79 & & 1098 & 8.16 \\
\hline 0.264 & 388 & 9.81 & & 1099 & 7.15 \\
\hline 0.266 & 393 & 10.00 & & 1115 & 5.24 \\
\hline 0.266 & 393 & 9.90 & & 1112 & 4.32 \\
\hline 0.264 & 383 & 9.77 & & 1085 & 14.51 \\
\hline 0.264 & 383 & 9.74 & & 1084 & 16.09 \\
\hline 0.264 & 373 & 9.96 & & 1065 & 34.57 \\
\hline 0.264 & 373 & 9.92 & & 1064 & 39.34 \\
\hline \multicolumn{4}{|c|}{ 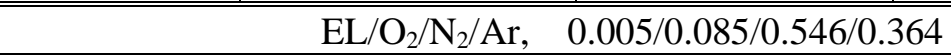 } & \multicolumn{2}{|l|}{$\phi 0.5$} \\
\hline$\overline{0.264}$ & 373 & 9.93 & & 1073 & $\overline{8.36}$ \\
\hline 0.264 & 373 & 10.25 & & 1078 & 8.79 \\
\hline 0.264 & 373 & 10.29 & & 1079 & 9.52 \\
\hline 0.264 & 383 & 10.04 & & 1097 & 2.98 \\
\hline 0.264 & 383 & 10.17 & & 1101 & 3.15 \\
\hline 0.264 & 383 & 10.20 & & 1102 & 2.78 \\
\hline 0.264 & 393 & 10.00 & & 1121 & 0.98 \\
\hline 0.264 & 393 & 10.29 & & 1130 & 1.10 \\
\hline 0.264 & 393 & 10.22 & & 1128 & 1.43 \\
\hline 0.257 & 363 & 9.70 & & 1048 & 39.21 \\
\hline 0.257 & 363 & 9.79 & & 1051 & 35.91 \\
\hline
\end{tabular}

Table 1. Rapid compression machine initial and compressed conditions, and ignition delay times. *Mixture composition is EL/O $\mathrm{O}_{2} / \mathrm{N}_{2} / \mathrm{Ar}, 0.005 / 0.0425 / 0.381 / 0.5715$. 


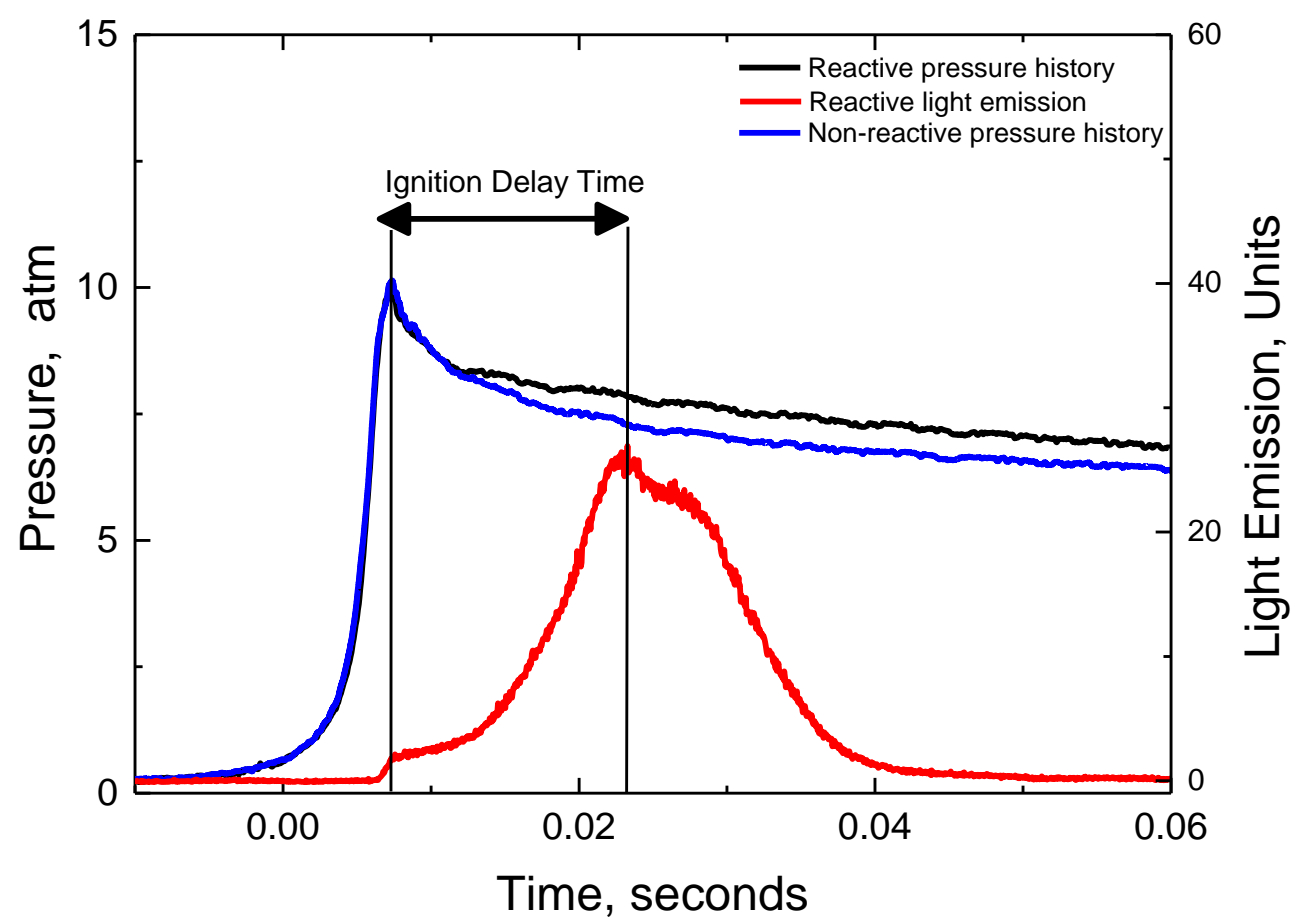

Figure 2. Exemplar rapid compression machine experimental (pressure and light) histories for compressed conditions of 9.74 atm and $1084 \mathrm{~K}, \mathrm{EL} / \mathrm{O}_{2} / \mathrm{N}_{2} / \mathrm{Ar}, 0.005 / 0.0425 / 0.6185 / 0.334, \phi=1.0$.

The experimental configuration of the high pressure shock tube (HPST) facility at KAUST has been detailed elsewhere [16]. The stainless steel HPST with inner diameter of $10 \mathrm{~cm}$, driven section of $6.6 \mathrm{~m}$ and a driver section that can be varied in length to $6.6 \mathrm{~m}$. For these intended $10 \mathrm{bar}$ reflected shock pressures, the driver and driven sections are separated by a mid-section which holds two pre-scored $0.13 \mathrm{~mm}$ aluminium diaphragms. Five equally separated PCB $113 \mathrm{~B} 26$ piezoelectric pressure transducers (PZT) are placed axially in the last $1.5 \mathrm{~m}$ of the driven section to measure incident shock velocity. The pressure history inside the shock tube is recorded using a Kistler 603B1 piezoelectric transducer located $1 \mathrm{~cm}$ away from the end-wall. $\mathrm{OH}^{*}$ chemiluminescence at $306 \mathrm{~nm}$ is monitored using a modified photodetector (Thorlabs PDA36A) through a sapphire window at the side-wall.

Two stainless steel mixing vessels attached to the driven section are used to prepare gaseous $\mathrm{EL} / \mathrm{O}_{2} / \mathrm{Ar}$ mixtures. The driven section of the shock tube, the mixing vessels and the connecting tubes 
are heated to $110{ }^{\circ} \mathrm{C}$ to avoid condensation of ethyl levulinate. Ethyl levulinate is injected into the evacuated and heated $\left(110{ }^{\circ} \mathrm{C}\right)$ stainless steel mixing vessels with its partial pressure kept at twothirds or less of the saturation vapor pressure. Oxygen (99.999\%) and argon (99.999\%) are manometrically mixed with the fuel in the mixing. A magnetically driven stirrer is used for at least one hour to produce homogeneous mixtures.

The driver section is pressurized with helium and the mid-section with helium at half the pressure of the driver section. The shock wave is then initiated by venting the mid-section, causing the diaphragms to rupture due to the resulting pressure gradient. This procedure is repeated at various gradients to induce a range of shock velocities producing the reflected shock conditions and ignition delay times given in Table 2 .

In the shock tube study, the ignition delay time is defined as the time from the arrival of the reflected shock wave at the side-wall to the subsequent maximum rate of change of pressure or $\mathrm{OH}^{*}$ emission. Ignition delay times calculated using the pressure and $\mathrm{OH}^{*}$ signal generally differed by less than $3 \%$. However, due to the dilute mixtures used here, the pressure increase at ignition was relatively small at the lower temperatures studied and the $\mathrm{OH}^{*}$ signal provides for a more precise determination of the onset of ignition. A representative ignition delay time measurement is shown in Figure 3. The experimental uncertainty is $\pm 0.7 \%$ in reported temperatures, $\pm 1 \%$ in reported pressures, $\pm 20 \%$ in reported ignition delay times and $\pm 2 \%$ in reported mixture fractions. 


\begin{tabular}{c|c|c}
\hline $\begin{array}{c}\text { Pressure / } \\
\text { bar }\end{array}$ & $\begin{array}{c}\text { Temperature / } \\
\mathrm{K}\end{array}$ & $\begin{array}{c}\text { Ignition Delay Time } \\
/ \mathrm{ms}\end{array}$ \\
\hline \multicolumn{2}{c}{$\mathrm{EL} / \mathrm{O}_{2} / \mathrm{Ar}, 0.005 / 0.0425 / 0.9525, \phi 1.0$} \\
\hline \hline 9.1 & 1391 & 0.070 \\
10.4 & 1352 & 0.164 \\
10.3 & 1311 & 0.293 \\
10.4 & 1274 & 0.418 \\
10.4 & 1250 & 0.577 \\
10.5 & 1204 & 1.057 \\
\hline \hline \multicolumn{3}{c}{$\mathrm{EL} / \mathrm{O}_{2} / \mathrm{Ar}, 0.005 / 0.085 / 0.91, \phi 0.5$} \\
\hline \hline 10.6 & 1340 & 0.117 \\
10.4 & 1324 & 0.146 \\
10.4 & 1250 & 0.426 \\
9.7 & 1236 & 0.507 \\
10.2 & 1213 & 0.693 \\
10.3 & 1185 & 1.014 \\
9.9 & 1150 & 1.590 \\
9.8 & 1131 & 2.213 \\
9.9 & 1125 & 2.702 \\
10.0 & 1116 & 2.610 \\
\hline \hline
\end{tabular}

Table 2. Shock tube compressed conditions and ignition delays times.

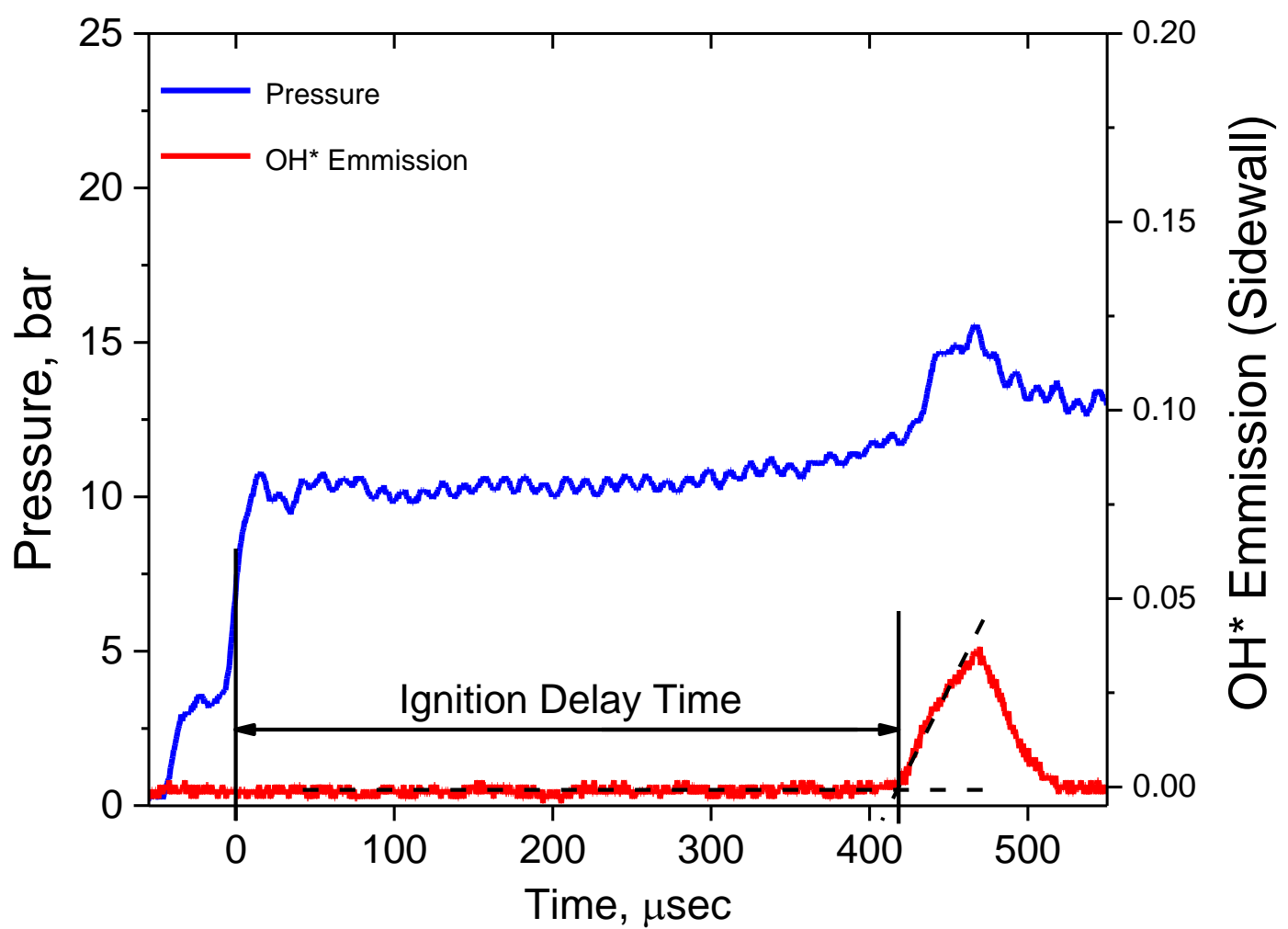

Figure 3. Exemplar shock tube experimental (pressure and light) histories for compressed conditions of $10.4 \mathrm{bar}$ and $1250 \mathrm{~K}, \mathrm{EL} / \mathrm{O}_{2} / \mathrm{Ar}, 0.005 / 0.085 / 0.91, \phi=0.5$. 


\section{Computational Methods}

For oxygenated hydrocarbons bearing the ethyl ester or methyl ketone functionalities, reliable thermochemical quantities already exist $[4,5]$, and are most conveniently utilised in the context of chemical group additivity. To estimate ethyl levulinate thermochemistry, one can use the thermochemistry of 2-butanone as methyl ketone (atoms 1-3 in Figure 1) and ethyl propanoate as ethyl ester (atoms 4-7 in Figure 1) functionalities respectively. However, the thermochemical properties of the methylene groups located between the ethyl-ester and methyl-ketone moieties of ethyl levulinate present unstudied identities within the context of combustion kinetics. Consequently, it is expected that existing thermochemical group contributions available to estimate radical formation enthalpies associated with these identities are inappropriate.

Therefore, a complete set of molecule and radical formation enthalpies for the ethyl levulinate pyrolysis system are pursued by computational chemistry methods [3]. When combined with wellknown reference values for small radicals, this data also produces reliable estimates of the bond dissociation energies of ethyl levulinate that are essential components of the kinetic model, particularly in the assignment of hydrogen abstraction rate constants. The computational chemistry methods give chemically accurate values and it involves several different levels of theory (i.e. CBSQB3, CBS-APNO, and G4MP2), the findings are summarised in Table 3. Both CBS-QB3 and CBSAPNO methodologies have been routinely employed to compute gas phase thermochemistry to expected accuracy of close to $2 \mathrm{kcal} / \mathrm{mol}[17,18]$. Though this is certainly the case, Simmie and Sommers $[17,18]$ show that both methods produce bias values when compared to a reference data base of expensively produced G4 and experimental values. They also show the average of these three methods (G4, CBS-QB3 and CBS-APNO) can be expected to give a more accurate estimate of the true value. This highlights that the use of either CBS-QB3 or CBS-APNO individually is unlikely to produce a chemically accurate outcome. In researching this issue we noticed that the use of the highly accurate, but comparatively inexpensive G4MP2 method is significantly undocumented for the determination of combustion thermochemistry. We show in an associated paper [3] that CBS-QB3, 
CBS-APNO and G4MP2 computed results can be combined to produce chemically accurate formation enthalpies for oxygenated hydrocarbons with the isodemsic worked reaction methodology, but that neither method can produce chemical accurate results in isolation. A detailed description of those findings is too large to be included in the scope of the current contribution and is reported separately, and available from the authors upon request [3].

\begin{tabular}{|c|c|}
\hline Species & $\begin{array}{c}\text { Average } \\
\text { (CBS-QB3 + CBS-APNO + G4MP2) } \\
\end{array}$ \\
\hline \multicolumn{2}{|c|}{ Molecules } \\
\hline $\mathrm{CH}_{3} \mathrm{C}(\mathrm{O}) \mathrm{CH}_{2} \mathrm{CH}_{2} \mathrm{C}(\mathrm{O}) \mathrm{OCH}_{2} \mathrm{CH}_{3}$ & -148.1 \\
\hline $\mathrm{CH}_{3} \mathrm{C}(\mathrm{O}) \mathrm{CH}_{2} \mathrm{CH}_{2} \mathrm{C}(\mathrm{O}) \mathrm{OH}$ & -145.3 \\
\hline $\mathrm{CH}_{3} \mathrm{C}(\mathrm{O}) \mathrm{CH}_{2} \mathrm{CH}_{2} \mathrm{C}(\mathrm{O}) \mathrm{OCH}_{3}$ & -140.0 \\
\hline \multicolumn{2}{|c|}{ Alkyl and Alkoxy Radicals Derived From Ethyl Levulinate $C-C$ and $C-O$ Fissior } \\
\hline $\mathrm{CH}_{3} \mathrm{C}(\mathrm{O}) \mathrm{CH}_{2} \mathrm{CH}_{2} \dot{\mathrm{C}}(\mathrm{O})$ & -45.0 \\
\hline $\mathrm{CH}_{3} \mathrm{C}(\mathrm{O}) \mathrm{CH}_{2} \mathrm{CH}_{2} \mathrm{C}(\mathrm{O}) \dot{\mathrm{O}}$ & -88.0 \\
\hline $\mathrm{CH}_{3} \mathrm{C}(\mathrm{O}) \mathrm{CH}_{2} \mathrm{CH}_{2} \mathrm{C}(\mathrm{O}) \mathrm{OC}_{2}$ & -93.7 \\
\hline$\dot{\mathrm{C}}(\mathrm{O}) \mathrm{CH}_{2} \mathrm{CH}_{2} \mathrm{C}(\mathrm{O}) \mathrm{OCH}_{2} \mathrm{CH}_{3}$ & -99.6 \\
\hline \multicolumn{2}{|c|}{ Alkyl Radicals Derived From Ethyl Levulinate $C-H$ Fission } \\
\hline$\dot{\mathrm{C}} \mathrm{H}_{2} \mathrm{C}(\mathrm{O}) \mathrm{CH}_{2} \mathrm{CH}_{2} \mathrm{C}(\mathrm{O}) \mathrm{OCH}_{2} \mathrm{CH}_{3}$ & -106.0 \\
\hline $\mathrm{CH}_{3} \mathrm{C}(\mathrm{O}) \dot{\mathrm{C}} \mathrm{HCH} \mathrm{H}_{2} \mathrm{C}(\mathrm{O}) \mathrm{OCH}_{2} \mathrm{CH}_{3}$ & -109.8 \\
\hline $\mathrm{CH}_{3} \mathrm{C}(\mathrm{O}) \mathrm{CH}_{2} \dot{\mathrm{C}} \mathrm{HC}(\mathrm{O}) \mathrm{OCH}_{2} \mathrm{CH}_{3}$ & -107.3 \\
\hline $\mathrm{CH}_{3} \mathrm{C}(\mathrm{O}) \mathrm{CH}_{2} \mathrm{CH}_{2} \mathrm{C}(\mathrm{O}) \mathrm{OC}_{\mathrm{C}} \mathrm{HCH}_{3}$ & -103.8 \\
\hline $\mathrm{CH}_{3} \mathrm{C}(\mathrm{O}) \mathrm{CH}_{2} \mathrm{CH}_{2} \mathrm{C}(\mathrm{O}) \mathrm{OCH}_{2} \dot{\mathrm{C}} \mathrm{H}_{2}$ & -99.1 \\
\hline
\end{tabular}

Table 3: Computed enthalpies of formation, $\Delta H_{f}^{0}(298.15 \mathrm{~K})(\mathrm{kcal} / \mathrm{mol})$ for radicals and molecules of the ethyl levulinate oxidation system employing isodesmic work reactions [3]

\subsection{Ethyl Levulinate Elimination to Ethylene and Levulinic Acid}

From prior studies on other ethyl esters [4], the concerted molecular elimination of the ester to form ethylene and an acid should reasonably be expected as a significant process for ethyl levulinate combustion. In order to underpin the importance of this process in the kinetic model described below, the potential energy surface for the molecular elimination of ethyl levulinate is also computed and presented in Figure 4. The minimum energy reaction pathways were determined by optimizing the geometries of the intermediates and transition states. To characterize all stationary points, the Hessian matrix (a matrix of energy second derivatives) was calculated and diagonalized at each stationary point, which also yielded zero-point energy (ZPE) corrections. The nature of the stationary points was 
evaluated from the harmonic modes and no imaginary frequencies were found for the optimized structures indicating that they correspond to the local minima on the potential energy surface. To follow the minimum energy path, also the called intrinsic reaction coordinate (IRC), the GonzalezSchlegel second-order method was used. IRC calculations were performed to examine the reaction path leading down from a transition structure in both directions on the potential energy surface to ensure that the transition states connected the desired reactants and products. Further, the normal modes corresponding to the transition-state structure were examined with molecular visualization to verify that nuclear motion tends to deform the transition-state structure along the pertinent reaction coordinate. The observation of a single imaginary frequency ensures that the identified transition state does indeed correspond to transformation of ethyl levulinate into levulinic acid and ethylene.

The potential energy surface shows that levulinic acid can be formed from ethyl levulinate by abstraction of an ethylene molecule through six-membered (TS1) or four-membered (TS2) transition states as shown in Figure 4. The reaction barrier of TS1 is calculated as 50.3, 50.2 and $50.1 \mathrm{kcal} / \mathrm{mol}$, and TS2 is calculated as $66.1,66.3$ and $65.6 \mathrm{kcal} / \mathrm{mol}$ at CBS-QB3, CBS-APNO and G4MP2 levels of theory, respectively. By averaging of these three methods, the favoured activation energy is $\mathbf{5 0 . 2}$ $\mathrm{kcal} / \mathrm{mol}$ for abstraction of an ethylene molecule from ethyl levulinate. The four-membered and sixmembered transition state structures were presented in Figure 5. The calculations show the reaction to be endothermic by 17.5 (at CBS-QB3), 17.1 (at CBS-APNO) and 15.9 (at G4MP2) kcal/mol. In similar fashion, the six-membered and four-membered transition state for ethylene abstraction from ethyl propanoate has been reported by El-Nahas et al. [4] as 50.2 and $66.2 \mathrm{kcal} / \mathrm{mol}$ and to be endothermic by $15.9 \mathrm{kcal} / \mathrm{mol}$ at CBS-QB3. Their analysis is, as expected, in close agreement with the values computed in this study for the ethyl levulinate system. 


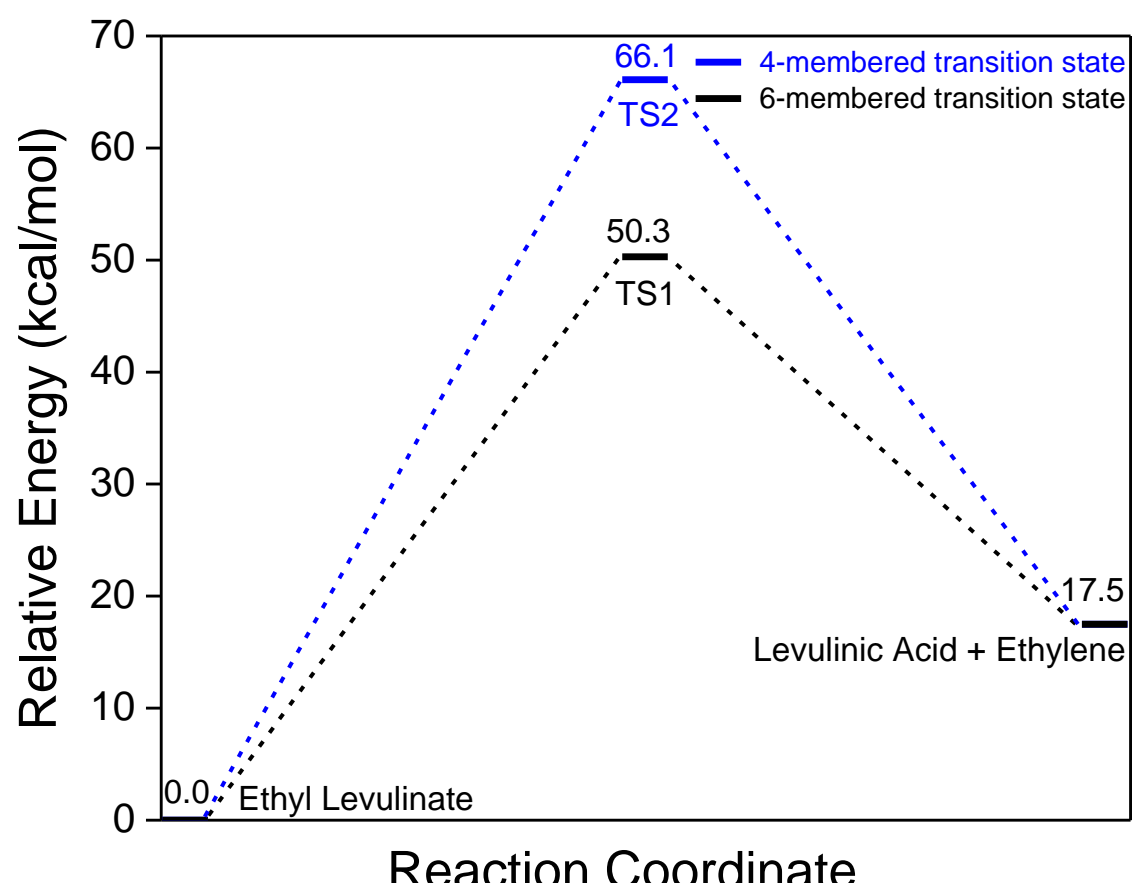

Figure 4. Potential energy surface for the reaction of ethyl levulinate elimination to ethylene and levulinic acid at the CBS-QB3 level of theory. Energies are in $\mathrm{kcal} / \mathrm{mol}$.
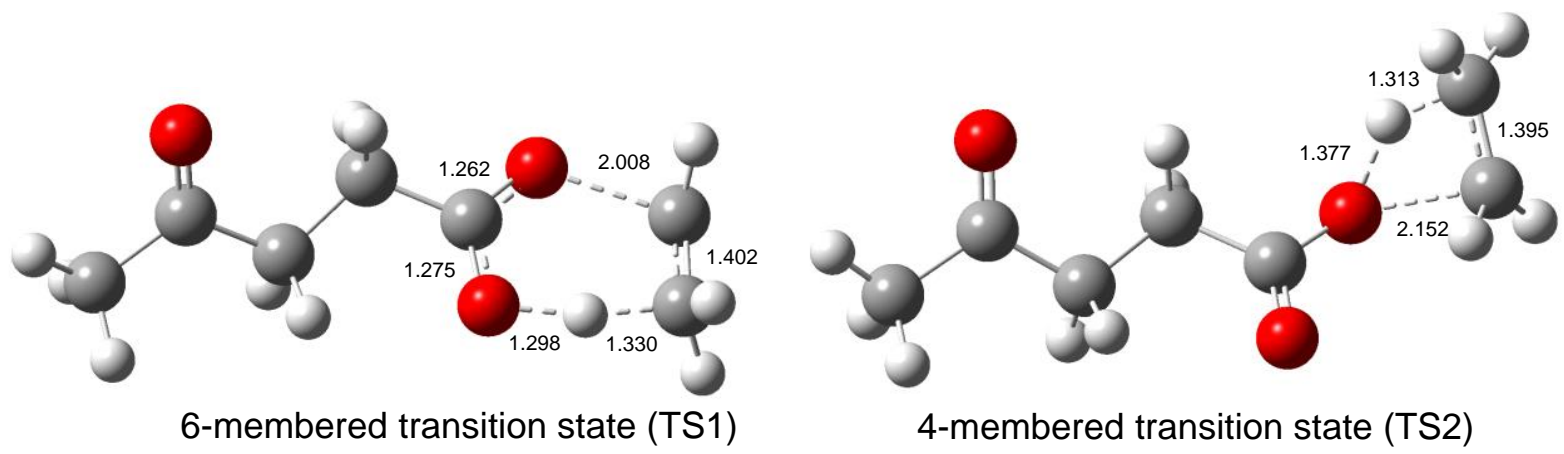

Figure 5. Six-membered (TS1) and four-membered (TS2) transition state structures for the elimination of ethyl levulinate to ethylene and levulinic acid.

\section{Combustion Kinetic Model Construction}

From a discrete molecular perspective, the combustion kinetics of levulinate ester chemical structures have not been studied before. The ethyl levulinate structure is markedly different to conventional paraffinic hydrocarbons, and other oxygenates as it bares both ketone, and ethyl ester functionalities in the same molecule. However, from the perspective of functional groups, both the 
methyl ketone, and ethyl ester moieties are quite well studied. Thus, having established the thermochemical environments of the species of the ethyl levulinate oxidation mechanism, the elementary reaction pathways, their rate constant expressions pertinent to ethyl levulinate combustion can be prescribed considering the best knowledge available for each discrete reaction center, as studied in these other, simpler systems. In general, for the ethyl levulinate reaction centers comprising the methyl ketone functionality (atoms 1-3 in Figure 1), rate constant parameters have been assigned by analogy to those of 2-butanone, and for those reaction centers comprising the ethyl ester functionality (atoms 4-7 in Figure 1), rate constant parameters have been assigned by analogy to those of the well-studied ethyl propanoate system. These are assigned principally by considering the modelling works of Serinyel et al. [19] and Metcalfe and co-workers [20, 21], for the methyl ketone and ethyl ester functionalities respectively. The appropriateness of the analogies imposed above is supported by a similarity in the thermochemical environment local to each reaction center as has been described above to within an apparent worse case consistency of $3.1 \mathrm{kcal} / \mathrm{mol}$.

The thermochemistry of all species produced by homolytic cleavage of ethyl levulinate, and their consumption products that are not described in the reaction submodel have been estimated by group additivity employing THERM [22]. The ketone group contributions are adopted from those reported by Hudzik et al. [5], and the ethyl ester contributions consistent with the finding of El-Nahas et al. [4] for the case of ethyl propanoate. These calculations result in a set of bond dissociation energies for ethyl levulinate, as shown by Figure 1. The formation enthalpy from these group additivity estimates is then adjusted to be equal to the theoretically calculated value we recommend in Table 3 above.

Reaction pathways have been prescribed by precise analogy to the descriptors used for the analogous reaction centers of 2-butanone and ethyl propanoate. Temperature dependent reaction rate constants are defined in the model with use of the modified Arrhenius equation, $k=A T^{n} \exp \left(-E_{a} /\right.$ $R T$ ) where, the frequency factor, A; the temperature, T; the activation energy, Ea; and the Universal 
Gas Constant, R. As is the norm in the field, this paper uses units of $\mathrm{cm}^{3} \mathrm{~mole}^{-1} \mathrm{~s}^{-1}, \mathrm{~K}$ and calories. In all cases, reactions are prescribed to be microscopically reversible, generally according to the protocols of Curran et al. [23, 24] e.g., where radical decomposition rate constants are estimated in the reverse exothermic direction $(\mathrm{P}+\mathrm{Q} \Rightarrow \mathrm{R})$ allowing the forward $(\mathrm{R}=>\mathrm{P}+\mathrm{Q})$ rate constant to be calculated from the equilibrium constant. The acquirement of accurate thermochemical parameters outlined above is essential to the fidelity of the rate constants estimated by this methodology.

Importantly, the gas phase reaction of ethyl esters has been repeatedly observed to be characterised by the concerted elimination of the ethyl group to form ethylene and the corresponding acid. For example, see the works of Blades and Gilderson [25], and Metcalfe et al. [20, 21], showing ethyl propanoate to decompose to ethylene and propanoic acid, and Westbrook et al. [26], who show the formation of formic acid and ethylene from ethyl formate decomposition. These findings are further evidenced by the works of Farooq et al. [27] who studied ethyl propanoate pyrolysis, and by the work of Ren et al. [28] who studied the thermal decomposition of a series of ethyl esters behind reflected shock waves. In all cases, the particular ethyl ester was concluded to eliminate to the acid and ethylene as the dominant process. Metcalfe et al. [21] refined the high pressure limit rate expression for the reaction ethyl propanoate $\Leftrightarrow$ propanoic acid + ethylene to $1.6 \times 10^{13} \times$ Exp $\left(\frac{50,000 \mathrm{cal} / \mathrm{mol}}{\mathrm{RT}}\right) \mathrm{s}^{-1}$. Westbrook had similarly found a rate expressions of $2.0 \times 10^{13} \times \operatorname{Exp}$ $\left(\frac{50,000 \mathrm{cal} / \mathrm{mol}}{\mathrm{RT}}\right)$ and $1.0 \times 10^{13} \times \mathrm{T}^{0.0} \times \operatorname{Exp}\left(\frac{50,000 \mathrm{cal} / \mathrm{mol}}{\mathrm{RT}}\right)$ to adequately describe the similar processes of ethyl acetate and ethyl formate respectively. An activation energy of $50.2 \mathrm{kcal} / \mathrm{mol}$ for ethyl levulinate elimination to levulinic acid and ethylene is also computed from theory [3]. As this is very similar to the $1.6 \times 10^{13} \times \mathrm{T}^{0.0} \times \operatorname{Exp}\left(\frac{50,000 \mathrm{cal} / \mathrm{mol}}{\mathrm{RT}}\right) \mathrm{s}^{-1}$ rate expression tested by Metcalfe et al. for ethyl propanoate, this rate expression is assigned to the reaction of ethyl levulinate $\Leftrightarrow$ levulinic acid and ethylene.

\subsection{Hydrogen Abstraction from Ethyl Levulinate}


From Figure 1 and Table 3, it is established that ethyl levulinate has a remarkable variety of weak covalent bonds. This is particularly the case with regard to its $\mathrm{C}-\mathrm{H}$ bonds, four out of the five of these are weaker than or equal to $\sim 96 \mathrm{kcal} / \mathrm{mol}$, the typical energy of a tertiary $\mathrm{C}-\mathrm{H}$ bond in paraffinic systems. This $\mathrm{C}-\mathrm{H}$ bonding environment is therefore a significant departure from the combustion kinetics experience base. In the present model, hydrogen abstraction from carbon atoms 1, 3, 4 and 6 (90.5-96.4 kcal/mol, Figure 1) have been prescribed reaction rate coefficients, on a per hydrogen atom basis, equivalent to those utilised for hydrogen abstraction from tertiary carbon atoms $[29,30]$. The importance of this assignment is discussed when analysing the kinetic model calculations.

\subsection{Levulinic Acid Submodel}

Levulinic acid is a major intermediate species in the combustion of ethyl levulinate. The thermochemistry of this molecule is analogous to that of ethyl levulinate with the exception of the acidic $\mathrm{O}-\mathrm{H}$ bond, which is expected to have a bond dissociation energy of $\sim 110 \mathrm{kcal} / \mathrm{mol}$. The hydrogen abstraction rate constants for this molecule have been assigned consistent with the prescription above to ethyl levulinate, with the acidic site being assumed as equivalent to a primary hydrogen atom. The entire ethyl levulinate and levulinic acid submodels are listed in Table 4. 


\begin{tabular}{|c|c|c|c|c|}
\hline Reaction & A & $\mathrm{n}$ & $\mathrm{E}_{a}$ & Reference \\
\hline \multicolumn{5}{|c|}{ Ethyl Levulinate Decomposition } \\
\hline $\mathrm{EL} 1 \mathrm{~J}+\dot{\mathrm{H}}+\mathrm{M} \Leftrightarrow \mathrm{EL}$ & $1 \times 10^{14}$ & 0.00 & 0.0 & High pressure limit, analogy to ethyl propanoate $[20,21]$. \\
\hline $\mathrm{EL} 3 \mathrm{~J}+\dot{\mathrm{H}}+\mathrm{M} \Leftrightarrow \mathrm{EL}$ & $1 \times 10^{14}$ & 0.00 & 0.0 & High pressure limit, analogy to ethyl propanoate $[20,21]$. \\
\hline $\mathrm{EL} 4 \mathrm{~J}+\dot{\mathrm{H}}+\mathrm{M} \Leftrightarrow \mathrm{EL}$ & $1 \times 10^{14}$ & 0.00 & 0.0 & High pressure limit, analogy to ethyl propanoate $[20,21]$. \\
\hline $\mathrm{EL6J}+\dot{\mathrm{H}}+\mathrm{M} \Leftrightarrow \mathrm{EL}$ & $1 \times 10^{14}$ & 0.00 & 0.0 & High pressure limit, analogy to ethyl propanoate $[20,21]$. \\
\hline EL7J $+\dot{H}+M \Leftrightarrow E L$ & $1 \times 10^{14}$ & 0.00 & 0.0 & High pressure limit, analogy to ethyl propanoate $[20,21]$. \\
\hline$\dot{\mathrm{C}} \mathrm{H}_{3}+\dot{\mathrm{C}}(\mathrm{O}) \mathrm{CH}_{2} \mathrm{CH}_{2} \mathrm{C}(\mathrm{O}) \mathrm{OCH}_{2} \mathrm{CH}_{3} \Leftrightarrow \mathrm{EL}$ & $3 \times 10^{13}$ & 0.00 & 0.0 & High pressure limit, analogy to ethyl propanoate $[20,21]$. \\
\hline $\mathrm{CH}_{3} \mathrm{C}(\mathrm{O}) \mathrm{CH}_{2} \dot{\mathrm{C}} \mathrm{H}_{2}+\dot{\mathrm{C}}(\mathrm{O}) \mathrm{OCH}_{2} \mathrm{CH}_{3} \Leftrightarrow \mathrm{EL}$ & $3 \times 10^{13}$ & 0.00 & 0.0 & High pressure limit, analogy to ethyl propanoate $[20,21]$. \\
\hline $\mathrm{CH}_{3} \mathrm{C}(\mathrm{O}) \mathrm{CH}_{2} \mathrm{CH}_{2} \dot{\mathrm{CO}}_{2}+\dot{\mathrm{C}}_{2} \mathrm{H}_{5} \Leftrightarrow \mathrm{EL}$ & $3 \times 10^{13}$ & 0.00 & 0.0 & High pressure limit, analogy to ethyl propanoate $[20,21]$ \\
\hline $\mathrm{EL} \Leftrightarrow \mathrm{CH}_{3} \mathrm{C}(\mathrm{O}) \mathrm{CH}_{2} \mathrm{CH}_{2} \mathrm{C}(\mathrm{O}) \mathrm{OH}+\mathrm{C}_{2} \mathrm{H}_{4}$ & $8 \times 10^{12}$ & 0.00 & 49,950 & See detailed description in text. \\
\hline \multicolumn{5}{|c|}{ Hydrogen Abstraction from Ethyl Levulinate by $\mathrm{H}$ atom } \\
\hline $\mathrm{EL}+\dot{\mathrm{H}} \Leftrightarrow \mathrm{EL} 1 \mathrm{~J}+\mathrm{H}_{2}$ & $1.81 \times 10^{6}$ & 2.40 & 2,583 & Assumed to be $3 \mathrm{x}$ hydrogen abstraction from tertiary carbon [29]. \\
\hline $\mathrm{EL}+\dot{\mathrm{H}} \Leftrightarrow \mathrm{EL} 3 \mathrm{~J}+\mathrm{H}_{2}$ & $1.20 \times 10^{6}$ & 2.40 & 2,583 & Assumed to be $2 \mathrm{x}$ hydrogen abstraction from tertiary carbon [29]. \\
\hline $\mathrm{EL}+\dot{\mathrm{H}} \Leftrightarrow \mathrm{EL} 4 \mathrm{~J}+\mathrm{H}_{2}$ & $1.20 \times 10^{6}$ & 2.40 & 2,583 & Assumed to be $2 \mathrm{x}$ hydrogen abstraction from tertiary carbon [29]. \\
\hline $\mathrm{EL}+\dot{\mathrm{H}} \Leftrightarrow \mathrm{EL} 6 \mathrm{~J}+\mathrm{H}_{2}$ & $1.20 \times 10^{6}$ & 2.40 & 2,583 & Assumed to be $2 \mathrm{x}$ hydrogen abstraction from tertiary carbon [29]. \\
\hline $\mathrm{EL}+\dot{\mathrm{H}} \Leftrightarrow \mathrm{EL7J}+\mathrm{H}_{2}$ & $6.03 \times 10^{5}$ & 2.54 & 6,756 & Assumed to be $3 \mathrm{x}$ hydrogen abstraction from primary carbon [29]. \\
\hline \multicolumn{5}{|c|}{ Hydrogen Abstraction from Ethyl Levulinate by Hydroxyl Radical } \\
\hline $\mathrm{EL}+\dot{\mathrm{OH}} \Leftrightarrow \mathrm{EL} 1 \mathrm{~J}+\mathrm{H}_{2} \mathrm{O}$ & $8.78 \times 10^{4}$ & 2.53 & $-1,659$ & Assumed to be $3 \times$ hydrogen abstraction from tertiary carbon [29]. \\
\hline $\mathrm{EL}+\dot{\mathrm{OH}} \Leftrightarrow \mathrm{EL} 3 \mathrm{~J}+\mathrm{H}_{2} \mathrm{O}$ & $5.85 \times 10^{4}$ & 2.53 & $-1,659$ & Assumed to be $2 \mathrm{x}$ hydrogen abstraction from tertiary carbon [29]. \\
\hline $\mathrm{EL}+\dot{\mathrm{OH}} \Leftrightarrow \mathrm{EL} 4 \mathrm{~J}+\mathrm{H}_{2} \mathrm{O}$ & $5.85 \times 10^{4}$ & 2.53 & $-1,659$ & Assumed to be $2 \mathrm{x}$ hydrogen abstraction from tertiary carbon [29]. \\
\hline $\mathrm{EL}+\dot{\mathrm{OH}} \Leftrightarrow \mathrm{EL} 6 \mathrm{~J}+\mathrm{H}_{2} \mathrm{O}$ & $5.85 \times 10^{4}$ & 2.53 & $-1,659$ & Assumed to be $2 \mathrm{x}$ hydrogen abstraction from tertiary carbon [29]. \\
\hline $\mathrm{EL}+\dot{\mathrm{OH}} \Leftrightarrow \mathrm{EL} 7 \mathrm{~J}+\mathrm{H}_{2} \mathrm{O}$ & $2.22 \times 10^{4}$ & 2.67 & -168.9 & Assumed to be $3 \times$ hydrogen abstraction from primary carbon [29]. \\
\hline \multicolumn{5}{|c|}{ Hydrogen Abstraction from Ethyl Levulinate by Methyl Radical } \\
\hline $\mathrm{EL}+\dot{\mathrm{C}} \mathrm{H}_{3} \Leftrightarrow \mathrm{EL} 1 \mathrm{~J}+\mathrm{CH}_{4}$ & 2.71 & 3.46 & 4598 & Assumed to be $3 \times$ hydrogen abstraction from tertiary carbon [29]. \\
\hline $\mathrm{EL}+\dot{\mathrm{C}} \mathrm{H}_{3} \Leftrightarrow \mathrm{EL} 3 \mathrm{~J}+\mathrm{CH}_{4}$ & 1.81 & 3.46 & 4598 & Assumed to be $2 \times$ hydrogen abstraction from tertiary carbon [29]. \\
\hline $\mathrm{EL}+\dot{\mathrm{C}} \mathrm{H}_{3} \Leftrightarrow \mathrm{EL} 4 \mathrm{~J}+\mathrm{CH}_{4}$ & 1.81 & 6.36 & 4598 & Assumed to be $2 \mathrm{x}$ hydrogen abstraction from tertiary carbon [29]. \\
\hline $\mathrm{EL}+\dot{\mathrm{C}} \mathrm{H}_{3} \Leftrightarrow \mathrm{EL} 6 \mathrm{~J}+\mathrm{CH}_{4}$ & 1.81 & 6.36 & 4598 & Assumed to be $2 \mathrm{x}$ hydrogen abstraction from tertiary carbon [29]. \\
\hline $\mathrm{EL}+\dot{\mathrm{C}} \mathrm{H}_{3} \Leftrightarrow \mathrm{EL} 7 \mathrm{~J}+\mathrm{CH}_{4}$ & 2.71 & 3.65 & 7,154 & Assumed to be $3 \mathrm{x}$ hydrogen abstraction from primary carbon [29]. \\
\hline \multicolumn{5}{|c|}{ Hydrogen Abstraction from Ethyl Levulinate by Methoxy Radical } \\
\hline $\mathrm{EL}+\mathrm{CH}_{3} \dot{\mathrm{O}} \Leftrightarrow \mathrm{EL} 1 \mathrm{~J}+\mathrm{CH}_{3} \mathrm{OH}$ & $5.70 \times 10^{10}$ & 0.00 & 2,800 & Assumed to be $3 \mathrm{x}$ hydrogen abstraction from tertiary carbon [29]. \\
\hline $\mathrm{EL}+\mathrm{CH}_{3} \mathrm{O} \Leftrightarrow \mathrm{EL} 3 \mathrm{~J}+\mathrm{CH}_{3} \mathrm{OH}$ & $3.80 \times 10^{10}$ & 0.00 & 2,800 & Assumed to be $2 \mathrm{x}$ hydrogen abstraction from tertiary carbon [29]. \\
\hline $\mathrm{EL}+\mathrm{CH}_{3} \mathrm{O} \Leftrightarrow \mathrm{EL} 4 \mathrm{~J}+\mathrm{CH}_{3} \mathrm{OH}$ & $3.80 \times 10^{10}$ & 0.00 & 2,800 & Assumed to be $2 \mathrm{x}$ hydrogen abstraction from tertiary carbon [29]. \\
\hline $\mathrm{EL}+\mathrm{CH}_{3} \dot{\mathrm{O}} \Leftrightarrow \mathrm{EL} 6 \mathrm{~J}+\mathrm{CH}_{3} \mathrm{OH}$ & $3.80 \times 10^{10}$ & 0.00 & 2,800 & Assumed to be $2 \mathrm{x}$ hydrogen abstraction from tertiary carbon [29]. \\
\hline $\mathrm{EL}+\mathrm{CH}_{3} \mathrm{O} \Leftrightarrow \mathrm{EL} 7 \mathrm{~J}+\mathrm{CH}_{3} \mathrm{OH}$ & $1.60 \times 10^{11}$ & 0.00 & 7,000 & Assumed to be $3 \times$ hydrogen abstraction from primary carbon [29]. \\
\hline
\end{tabular}




\begin{tabular}{|c|c|c|c|c|}
\hline $\mathrm{EL}+\mathrm{CH}_{3} \dot{\mathrm{O}}_{2} \Leftrightarrow \mathrm{EL} 1 \mathrm{~J}+\mathrm{CH}_{3} \mathrm{O}_{2} \mathrm{H}$ & $4.10 \times 10^{2}$ & 3.12 & 13,190 & Assumed to be $3 \mathrm{x}$ hydrogen abstraction from tertiary carbon [29]. \\
\hline $\mathrm{EL}+\mathrm{CH}_{3} \dot{\mathrm{O}}_{2} \Leftrightarrow \mathrm{EL} 3 \mathrm{~J}+\mathrm{CH}_{3} \mathrm{O}_{2} \mathrm{H}$ & $2.73 \times 10^{2}$ & 3.12 & 13,190 & Assumed to be $2 \mathrm{x}$ hydrogen abstraction from tertiary carbon [29]. \\
\hline $\mathrm{EL}+\mathrm{CH}_{3} \dot{\mathrm{O}}_{2} \Leftrightarrow \mathrm{EL} 4 \mathrm{~J}+\mathrm{CH}_{3} \mathrm{O}_{2} \mathrm{H}$ & $2.73 \times 10^{2}$ & 3.12 & 13,190 & Assumed to be $2 \mathrm{x}$ hydrogen abstraction from tertiary carbon [29]. \\
\hline $\mathrm{EL}+\mathrm{CH}_{3} \dot{\mathrm{O}}_{2} \Leftrightarrow \mathrm{EL} 6 \mathrm{~J}+\mathrm{CH}_{3} \mathrm{O}_{2} \mathrm{H}$ & $2.73 \times 10^{2}$ & 3.12 & 13,190 & Assumed to be $2 \times$ hydrogen abstraction from tertiary carbon [29]. \\
\hline $\mathrm{EL}+\mathrm{CH}_{3} \dot{\mathrm{O}}_{2} \Leftrightarrow \mathrm{EL} 7 \mathrm{~J}+\mathrm{CH}_{3} \mathrm{O}_{2} \mathrm{H}$ & $6.93 \times 10^{-1}$ & 3.97 & 18,280 & Assumed to be $3 \mathrm{x}$ hydrogen abstraction from primary carbon [29]. \\
\hline \multicolumn{5}{|c|}{ Hydrogen Abstraction from Ethyl Levulinate by Hydroxyl Radical } \\
\hline $\mathrm{EL}+\mathrm{HO}_{2} \Leftrightarrow \mathrm{EL} 1 \mathrm{~J}+\mathrm{H}_{2} \mathrm{O}_{2}$ & $1.30 \times 10^{3}$ & 3.01 & 12,090 & Assumed to be $3 \mathrm{x}$ hydrogen abstraction from tertiary carbon [29]. \\
\hline $\mathrm{EL}+\mathrm{HO}_{2} \Leftrightarrow \mathrm{EL} 3 \mathrm{~J}+\mathrm{H}_{2} \mathrm{O}_{2}$ & $8.66 \times 10^{2}$ & 3.01 & 12,090 & Assumed to be $2 \times$ hydrogen abstraction from tertiary carbon [29]. \\
\hline $\mathrm{EL}+\mathrm{HO}_{2} \Leftrightarrow \mathrm{EL} 4 \mathrm{~J}+\mathrm{H}_{2} \mathrm{O}_{2}$ & $8.66 \times 10^{2}$ & 3.01 & 12,090 & Assumed to be $2 \times$ hydrogen abstraction from tertiary carbon [29]. \\
\hline $\mathrm{EL}+\mathrm{HO}_{2} \Leftrightarrow \mathrm{EL} 6 \mathrm{~J}+\mathrm{H}_{2} \mathrm{O}_{2}$ & $8.66 \times 10^{2}$ & 3.01 & 12,090 & Assumed to be $2 \mathrm{x}$ hydrogen abstraction from tertiary carbon [29]. \\
\hline $\mathrm{EL}+\mathrm{HO}_{2} \Leftrightarrow \mathrm{EL} 7 \mathrm{~J}+\mathrm{H}_{2} \mathrm{O}_{2}$ & $2.04 \times 10^{1}$ & 3.59 & 17,160 & Assumed to be $3 \times$ hydrogen abstraction from primary carbon [29]. \\
\hline \multicolumn{5}{|c|}{ Hydrogen Abstraction from Ethyl Levulinate by $O$ atom } \\
\hline $\mathrm{EL}+\ddot{\mathrm{O}} \Leftrightarrow \mathrm{EL} 1 \mathrm{~J}+\dot{\mathrm{O} H}$ & $5.90 \times 10^{5}$ & 2.40 & 1,150 & Assumed to be $3 \mathrm{x}$ hydrogen abstraction from tertiary carbon [29]. \\
\hline $\mathrm{EL}+\ddot{\mathrm{O}} \Leftrightarrow \mathrm{EL} 3 \mathrm{~J}+\dot{\mathrm{O} H}$ & $3.94 \times 10^{5}$ & 2.40 & 1,150 & Assumed to be $2 \times$ hydrogen abstraction from tertiary carbon [29]. \\
\hline $\mathrm{EL}+\ddot{\mathrm{O}} \Leftrightarrow \mathrm{EL} 4 \mathrm{~J}+\dot{\mathrm{O} H}$ & $3.94 \times 10^{5}$ & 2.40 & 1,150 & Assumed to be $2 \mathrm{x}$ hydrogen abstraction from tertiary carbon [29]. \\
\hline $\mathrm{EL}+\ddot{\mathrm{O}} \Leftrightarrow \mathrm{EL} 6 \mathrm{~J}+\dot{\mathrm{O} H}$ & $3.94 \times 10^{5}$ & 2.40 & 1,150 & Assumed to be $2 \mathrm{x}$ hydrogen abstraction from tertiary carbon [29]. \\
\hline $\mathrm{EL}+\ddot{\mathrm{O}} \Leftrightarrow \mathrm{EL} 7 \mathrm{~J}+\dot{\mathrm{O} H}$ & $1.35 \times 10^{7}$ & 2.03 & 5,136 & Assumed to be $3 \times$ hydrogen abstraction from primary carbon [29]. \\
\hline \multicolumn{5}{|c|}{ Hydrogen Abstraction from Ethyl Levulinate by Molecular Oxygen } \\
\hline $\mathrm{EL}+\mathrm{O}_{2} \Leftrightarrow \mathrm{EL} 1 \mathrm{~J}+\mathrm{HO}_{2}$ & $3.00 \times 10^{13}$ & 0.00 & 48,200 & Assumed to be $3 \times$ hydrogen abstraction from tertiary carbon [29]. \\
\hline $\mathrm{EL}+\mathrm{O}_{2} \Leftrightarrow \mathrm{EL} 3 \mathrm{~J}+\mathrm{HO}_{2}$ & $2.00 \times 10^{13}$ & 0.00 & 48,200 & Assumed to be $2 \mathrm{x}$ hydrogen abstraction from tertiary carbon [29]. \\
\hline $\mathrm{EL}+\mathrm{O}_{2} \Leftrightarrow \mathrm{EL} 4 \mathrm{~J}+\mathrm{HO}_{2}$ & $2.00 \times 10^{13}$ & 0.00 & 48,200 & Assumed to be $2 \times$ hydrogen abstraction from tertiary carbon [29]. \\
\hline $\mathrm{EL}+\mathrm{O}_{2} \Leftrightarrow \mathrm{EL} 6 \mathrm{~J}+\mathrm{HO}_{2}$ & $2.00 \times 10^{13}$ & 0.00 & 48,200 & Assumed to be $2 \mathrm{x}$ hydrogen abstraction from tertiary carbon [29]. \\
\hline $\mathrm{EL}+\mathrm{O}_{2} \Leftrightarrow \mathrm{EL} 7 \mathrm{~J}+\mathrm{HO}_{2}$ & $3.00 \times 10^{13}$ & 0.00 & 52,290 & Assumed to be $3 \times$ hydrogen abstraction from primary carbon [29]. \\
\hline \multicolumn{5}{|c|}{ Ethyl Levulinate Alkyl and Akloxy Radical Beta-bond Scissions } \\
\hline $\mathrm{CH}_{2} \mathrm{C}(\mathrm{O})+\dot{\mathrm{C}} \mathrm{H}_{2} \mathrm{CH}_{2} \mathrm{C}(\mathrm{O}) \mathrm{OCH}_{2} \mathrm{CH}_{3} \Leftrightarrow \mathrm{EL} 1 \mathrm{~J}$ & $1.00 \times 10^{11}$ & 0.00 & 6,000 & Analogy to $\dot{\mathrm{C}} \mathrm{H}_{3}+\mathrm{CH}_{2} \mathrm{CO} \Leftrightarrow \mathrm{CH}_{3} \mathrm{CO} \dot{C} \mathrm{H}_{2}[29]$. \\
\hline$\dot{\mathrm{C}} \mathrm{H}_{3}+\mathrm{C}(\mathrm{O}) \mathrm{CHCH}_{2} \mathrm{C}(\mathrm{O}) \mathrm{OCH}_{2} \mathrm{CH}_{3} \Leftrightarrow \mathrm{EL} 3 \mathrm{~J}$ & $1.00 \times 10^{11}$ & 2.48 & 6,130 & Analogy to $\dot{\mathrm{C}} \mathrm{H}_{3}+\mathrm{CH}_{2} \mathrm{CO} \Leftrightarrow \mathrm{CH}_{3} \mathrm{CO} \dot{C}_{2}[29]$. \\
\hline $\mathrm{CH}_{3} \dot{\mathrm{C}}(\mathrm{O})+\mathrm{CH}_{2} \mathrm{CHC}(\mathrm{O}) \mathrm{OCH}_{2} \mathrm{CH}_{3} \Leftrightarrow \mathrm{EL} 4 \mathrm{~J}$ & $1.00 \times 10^{11}$ & 0.00 & 8,420 & Analogy to $\mathrm{C}_{2} \mathrm{H}_{4}+\dot{\mathrm{CO}}_{2} \mathrm{CH}_{2} \mathrm{CH}_{3} \Leftrightarrow \dot{\mathrm{C}} \mathrm{H}_{2} \mathrm{CH}_{2} \mathrm{C}(\mathrm{O}) \mathrm{OCH}_{3}[20,21]$. \\
\hline $\mathrm{CH}_{3} \mathrm{C}(\mathrm{O}) \mathrm{CHCH}_{2}+\dot{\mathrm{C}}(\mathrm{O}) \mathrm{OCH}_{2} \mathrm{CH}_{3} \Leftrightarrow \mathrm{EL} 3 \mathrm{~J}$ & $1.32 \times 10^{4}$ & 2.48 & 6,130 & Analogy to $\mathrm{C}_{2} \mathrm{H}_{4}+\mathrm{CH}_{3} \dot{\mathrm{CO}} \Leftrightarrow \dot{\mathrm{C}} \mathrm{H}_{2} \mathrm{CH}_{2} \mathrm{COCH}_{3}[31]$. \\
\hline $\mathrm{CH}_{3} \mathrm{C}(\mathrm{O}) \mathrm{CH}_{2} \mathrm{CHC}(\mathrm{O})+\mathrm{C}_{2} \mathrm{H}_{5} \dot{\mathrm{O}} \Leftrightarrow \mathrm{EL} 4 \mathrm{~J}$ & $2.23 \times 10^{11}$ & 0.00 & 7,800 & Analogy to $\mathrm{C}_{2} \mathrm{H}_{4}+\mathrm{C}_{2} \mathrm{H}_{5} \dot{\mathrm{O}} \Leftrightarrow \mathrm{C}_{2} \mathrm{H}_{5} \mathrm{OCH}_{2} \dot{\mathrm{C}} \mathrm{H}_{2}[31]$. \\
\hline $\mathrm{CH}_{3} \mathrm{C}(\mathrm{O}) \mathrm{CH}_{2} \mathrm{CH}_{2} \dot{\mathrm{C}}(\mathrm{O})+\mathrm{CH}_{3} \mathrm{CH}(\mathrm{O}) \Leftrightarrow$ EL6J & $2.002 \times 10^{12}$ & 0.00 & 24,000 & $\begin{array}{l}\text { Analogy to } \mathrm{CH}_{3} \mathrm{CHO}+\mathrm{CH}_{3} \mathrm{CH}_{2} \dot{\mathrm{C}}(\mathrm{O}) \Leftrightarrow \mathrm{CH}_{3} \dot{\mathrm{C}} \mathrm{H}_{2} \mathrm{C}(\mathrm{O}) \mathrm{OCH}_{2} \mathrm{CH}_{3} \\
\text { [29]. }\end{array}$ \\
\hline $\mathrm{CH}_{3} \mathrm{C}(\mathrm{O}) \mathrm{CH}_{2} \mathrm{CH}_{2} \mathrm{C}(\mathrm{O}) \dot{\mathrm{O}}+\mathrm{C}_{2} \mathrm{H}_{4} \Leftrightarrow$ EL7J & $1.32 \times 10^{4}$ & 2.48 & 6,130 & Analogy to $\mathrm{C}_{2} \mathrm{H}_{4}+\dot{\mathrm{CO}}_{2} \mathrm{CH}_{2} \mathrm{CH}_{3} \Leftrightarrow \dot{\mathrm{C}} \mathrm{H}_{2} \mathrm{CH}_{2} \mathrm{C}(\mathrm{O}) \mathrm{OCH}_{3}$ [29]. \\
\hline $\mathrm{CH}_{2} \mathrm{C}(\mathrm{O})+\dot{\mathrm{CH}}_{2} \mathrm{C}(\mathrm{O}) \mathrm{OCH}_{2} \mathrm{CH}_{3} \Leftrightarrow \dot{\mathrm{C}}(\mathrm{O}) \mathrm{CH}_{2} \mathrm{CH}_{2} \mathrm{C}(\mathrm{O}) \mathrm{OCH}_{2} \mathrm{CH}_{3}$ & $1.00 \times 10^{4}$ & 2.48 & 6,130 & Analogy to $\mathrm{C}_{2} \mathrm{H}_{4}+\dot{\mathrm{C}} \mathrm{H}_{2} \mathrm{C}(\mathrm{O}) \mathrm{OCH}_{3} \Leftrightarrow \dot{\mathrm{C}} \mathrm{H}_{2} \mathrm{C}(\mathrm{O}) \mathrm{OCH}_{3}[31]$. \\
\hline $\mathrm{CH}_{3} \mathrm{C}(\mathrm{O}) \dot{\mathrm{C}} \mathrm{H}_{2}+\mathrm{CH}_{2} \mathrm{CO} \Leftrightarrow \mathrm{CH}_{3} \mathrm{C}(\mathrm{O}) \mathrm{CH}_{2} \mathrm{CH}_{2} \dot{\mathrm{C}}(\mathrm{O})$ & $1.00 \times 10^{11}$ & 0.00 & 6,000 & Analogy to $\dot{\mathrm{C}} \mathrm{H}_{3}+\mathrm{CH}_{2} \mathrm{C}(\mathrm{O}) \Leftrightarrow \mathrm{CH}_{3} \mathrm{CO}^{-} \mathrm{CH}_{2}[29]$. \\
\hline $\mathrm{CH}_{3} \mathrm{C}(\mathrm{O}) \mathrm{CH}_{2} \dot{\mathrm{C}} \mathrm{H}_{2}+\mathrm{CO}_{2} \Leftrightarrow \mathrm{CH}_{3} \mathrm{C}(\mathrm{O}) \mathrm{CH}_{2} \mathrm{CH}_{2} \mathrm{C}(\mathrm{O}) \dot{\mathrm{O}}$ & $1.00 \times 10^{11}$ & 0.00 & 3,936 & Analogy to $\mathrm{CO}_{2}+\mathrm{CH}_{3} \mathrm{CH}_{2} \dot{\mathrm{C}} \mathrm{H}_{2} \Leftrightarrow \mathrm{CH}_{3} \mathrm{CH}_{2} \mathrm{CH}_{2} \mathrm{C}(\mathrm{O}) \dot{\mathrm{O}}$ [31]. \\
\hline $\mathrm{C}_{2} \mathrm{H}_{4}+\mathrm{CH}_{3} \dot{\mathrm{C}}(\mathrm{O}) \Leftrightarrow \dot{\mathrm{C}} \mathrm{H}_{2} \mathrm{CH}_{2} \mathrm{C}(\mathrm{O}) \mathrm{CH}_{3}$ & $1.00 \times 10^{11}$ & 0.00 & 8,420 & 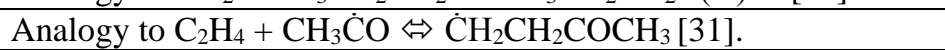 \\
\hline
\end{tabular}




\begin{tabular}{|c|c|c|c|c|}
\hline EL1J $\Leftrightarrow$ EL3J & $1.00 \times 10^{13}$ & 0.00 & 0.0 & Assumed to be in thermodynamic equilibrium [32]. \\
\hline EL1J $\Leftrightarrow$ EL4J & $1.00 \times 10^{13}$ & 0.00 & 0.0 & Assumed to be in thermodynamic equilibrium [32]. \\
\hline EL1J $\Leftrightarrow$ EL6J & $1.00 \times 10^{13}$ & 0.00 & 0.0 & Assumed to be in thermodynamic equilibrium [32]. \\
\hline EL1J $\Leftrightarrow$ EL7J & $1.00 \times 10^{13}$ & 0.00 & 0.0 & Assumed to be in thermodynamic equilibrium [32]. \\
\hline EL3J $\Leftrightarrow$ EL4J & $1.00 \times 10^{13}$ & 0.00 & 0.0 & Assumed to be in thermodynamic equilibrium [32]. \\
\hline EL3J $\Leftrightarrow$ EL6J & $1.00 \times 10^{13}$ & 0.00 & 0.0 & Assumed to be in thermodynamic equilibrium [32]. \\
\hline EL3J $\Leftrightarrow$ EL7J & $1.00 \times 10^{13}$ & 0.00 & 0.0 & Assumed to be in thermodynamic equilibrium [32]. \\
\hline EL4J $\Leftrightarrow$ EL6J & $1.00 \times 10^{13}$ & 0.00 & 0.0 & Assumed to be in thermodynamic equilibrium [32]. \\
\hline EL4J $\Leftrightarrow$ EL7J & $1.00 \times 10^{13}$ & 0.00 & 0.0 & Assumed to be in thermodynamic equilibrium [32]. \\
\hline EL6J $\Leftrightarrow$ EL7J & $1.00 \times 10^{13}$ & 0.00 & 0.0 & Assumed to be in thermodynamic equilibrium [32]. \\
\hline \multicolumn{5}{|c|}{ Levulinic Acid Decomposition } \\
\hline $\mathrm{CH}_{3} \mathrm{C}(\mathrm{O}) \mathrm{CH}_{2} \mathrm{CH}_{2} \mathrm{C}(\mathrm{O}) \dot{\mathrm{O}}+\dot{\mathrm{H}} \Leftrightarrow \mathrm{CH}_{3} \mathrm{C}(\mathrm{O}) \mathrm{CH}_{2} \mathrm{CH}_{2} \mathrm{C}(\mathrm{O}) \mathrm{OH}$ & $1.00 \times 10^{14}$ & 0.0 & 0.0 & High pressure limit, analogy to ethyl propanoate [20,21]. \\
\hline $\mathrm{CH}_{3} \mathrm{C}(\mathrm{O}) \mathrm{CH}_{2} \dot{\mathrm{C}} \mathrm{HC}(\mathrm{O}) \mathrm{OH}+\dot{\mathrm{H}} \Leftrightarrow \mathrm{CH}_{3} \mathrm{C}(\mathrm{O}) \mathrm{CH}_{2} \mathrm{CH}_{2} \mathrm{C}(\mathrm{O}) \mathrm{OH}$ & $1.00 \times 10^{14}$ & 0.0 & 0.0 & High pressure limit, analogy to ethyl propanoate $[20,21]$. \\
\hline $\mathrm{CH}_{3} \mathrm{C}(\mathrm{O}) \dot{\mathrm{C}} \mathrm{HCH}_{2} \mathrm{C}(\mathrm{O}) \mathrm{OH}+\dot{\mathrm{H}} \Leftrightarrow \mathrm{CH}_{3} \mathrm{C}(\mathrm{O}) \mathrm{CH}_{2} \mathrm{CH}_{2} \mathrm{C}(\mathrm{O}) \mathrm{OH}$ & $1.00 \times 10^{14}$ & 0.0 & 0.0 & High pressure limit, analogy to ethyl propanoate $[20,21]$. \\
\hline$\dot{\mathrm{C}} \mathrm{H}_{2} \mathrm{C}(\mathrm{O}) \mathrm{CH}_{2} \mathrm{CH}_{2} \mathrm{C}(\mathrm{O}) \mathrm{OH}+\dot{\mathrm{H}} \Leftrightarrow \mathrm{CH}_{3} \mathrm{C}(\mathrm{O}) \mathrm{CH}_{2} \mathrm{CH}_{2} \mathrm{C}(\mathrm{O}) \mathrm{OH}$ & $1.00 \times 10^{14}$ & 0.0 & 0.0 & High pressure limit, analogy to ethyl propanoate $[20,21]$. \\
\hline $\mathrm{CH}_{3} \mathrm{C}(\mathrm{O}) \mathrm{CH}_{2} \mathrm{CH}_{2} \dot{\mathrm{C}}(\mathrm{O})+\dot{\mathrm{OH}} \Leftrightarrow \mathrm{CH}_{3} \mathrm{C}(\mathrm{O}) \mathrm{CH}_{2} \mathrm{CH}_{2} \mathrm{C}(\mathrm{O}) \mathrm{OH}$ & $7.00 \times 10^{13}$ & 0.0 & 0.0 & High pressure limit, analogy to ethyl propanoate $[20,21]$. \\
\hline $\mathrm{CH}_{3} \mathrm{C}(\mathrm{O}) \mathrm{CH}_{2} \mathrm{CH}_{2} \dot{\mathrm{C}}(\mathrm{O})+\dot{\mathrm{O} H} \Leftrightarrow \mathrm{CH}_{3} \mathrm{C}(\mathrm{O}) \mathrm{CH}_{2} \mathrm{CH}_{2} \mathrm{C}(\mathrm{O}) \mathrm{OH}$ & $7.00 \times 10^{13}$ & 0.0 & 0.0 & High pressure limit, analogy to ethyl propanoate $[20,21]$. \\
\hline $\mathrm{CH}_{3} \mathrm{C}(\mathrm{O}) \mathrm{CH}_{2} \dot{\mathrm{C}} \mathrm{H}_{2}+\dot{\mathrm{C}}(\mathrm{O}) \mathrm{OH} \Leftrightarrow \mathrm{CH}_{3} \mathrm{C}(\mathrm{O}) \mathrm{CH}_{2} \mathrm{CH}_{2} \mathrm{C}(\mathrm{O}) \mathrm{OH}$ & $3.00 \times 10^{13}$ & 0.0 & 0.0 & High pressure limit, analogy to ethyl propanoate $[20,21]$. \\
\hline $\mathrm{CH}_{3} \mathrm{C}(\mathrm{O}) \dot{\mathrm{C}} \mathrm{H}_{2}+\dot{\mathrm{C}} \mathrm{H}_{2} \mathrm{C}(\mathrm{O}) \mathrm{OH} \Leftrightarrow \mathrm{CH}_{3} \mathrm{C}(\mathrm{O}) \mathrm{CH}_{2} \mathrm{CH}_{2} \mathrm{C}(\mathrm{O}) \mathrm{OH}$ & $3.00 \times 10^{13}$ & 0.0 & 0.0 & High pressure limit, analogy to ethyl propanoate $[20,21]$. \\
\hline $\mathrm{CH}_{3} \dot{\mathrm{C}}(\mathrm{O})+\dot{\mathrm{C}} \mathrm{H}_{2} \mathrm{CH}_{2} \mathrm{C}(\mathrm{O}) \mathrm{OH} \Leftrightarrow \mathrm{CH}_{3} \mathrm{C}(\mathrm{O}) \mathrm{CH}_{2} \mathrm{CH}_{2} \mathrm{C}(\mathrm{O}) \mathrm{OH}$ & $3.00 \times 10^{13}$ & 0.0 & 0.0 & High pressure limit, analogy to ethyl propanoate $[20,21]$. \\
\hline$\dot{\mathrm{C}} \mathrm{H}_{3}+\dot{\mathrm{C}}(\mathrm{O}) \mathrm{CH}_{2} \mathrm{CH}_{2} \mathrm{C}(\mathrm{O}) \mathrm{OH} \Leftrightarrow \mathrm{CH}_{3} \mathrm{C}(\mathrm{O}) \mathrm{CH}_{2} \mathrm{CH}_{2} \mathrm{C}(\mathrm{O}) \mathrm{OH}$ & $3.00 \times 10^{13}$ & 0.0 & 0.0 & High pressure limit, analogy to ethyl propanoate $[20,21]$. \\
\hline \multicolumn{5}{|c|}{ Hydrogen Abstraction from Levulinic Acid by Hydrogen Atom } \\
\hline $\mathrm{CH}_{3} \mathrm{C}(\mathrm{O}) \mathrm{CH}_{2} \mathrm{CH}_{2} \mathrm{C}(\mathrm{O}) \mathrm{OH}+\dot{\mathrm{H}} \Leftrightarrow \mathrm{CH}_{3} \mathrm{C}(\mathrm{O}) \mathrm{CH}_{2} \mathrm{CH}_{2} \mathrm{C}(\mathrm{O}) \dot{\mathrm{O}}+\mathrm{H}_{2}$ & $2.01 \times 10^{5}$ & 2.54 & 6,756 & Assumed to be $1 \mathrm{x}$ hydrogen abstraction from primary carbon [29]. \\
\hline $\mathrm{CH}_{3} \mathrm{C}(\mathrm{O}) \mathrm{CH}_{2} \mathrm{CH}_{2} \mathrm{C}(\mathrm{O}) \mathrm{OH}+\dot{\mathrm{H}} \Leftrightarrow \mathrm{CH}_{3} \mathrm{C}(\mathrm{O}) \mathrm{CH}_{2} \dot{\mathrm{C}} \mathrm{HC}(\mathrm{O}) \mathrm{OH}+\mathrm{H}_{2}$ & $1.20 \times 10^{6}$ & 2.40 & 2,583 & Assumed to be $2 \mathrm{x}$ hydrogen abstraction from tertiary carbon [29]. \\
\hline $\mathrm{CH}_{3} \mathrm{C}(\mathrm{O}) \mathrm{CH}_{2} \mathrm{CH}_{2} \mathrm{C}(\mathrm{O}) \mathrm{OH}+\dot{\mathrm{H}} \Leftrightarrow \mathrm{CH}_{3} \mathrm{C}(\mathrm{O}) \dot{\mathrm{C}} \mathrm{HCH}_{2} \mathrm{C}(\mathrm{O}) \mathrm{OH}+\mathrm{H}_{2}$ & $1.20 \times 10^{6}$ & 2.40 & 2,583 & Assumed to be $2 \mathrm{x}$ hydrogen abstraction from tertiary carbon [29]. \\
\hline $\mathrm{CH}_{3} \mathrm{C}(\mathrm{O}) \mathrm{CH}_{2} \mathrm{CH}_{2} \mathrm{C}(\mathrm{O}) \mathrm{OH}+\dot{\mathrm{H}} \Leftrightarrow \dot{\mathrm{C}} \mathrm{H}_{2} \mathrm{C}(\mathrm{O}) \mathrm{CH}_{2} \mathrm{CH}_{2} \mathrm{C}(\mathrm{O}) \mathrm{OH}+\mathrm{H}_{2}$ & $1.80 \times 10^{6}$ & 2.40 & 2,583 & Assumed to be $3 \mathrm{x}$ hydrogen abstraction from tertiary carbon [29]. \\
\hline \multicolumn{5}{|c|}{ Hydrogen Abstraction from Levulinic Acid by Hydrogen Atom } \\
\hline $\mathrm{CH}_{3} \mathrm{C}(\mathrm{O}) \mathrm{CH}_{2} \mathrm{CH}_{2} \mathrm{C}(\mathrm{O}) \mathrm{OH}+\dot{\mathrm{O} H} \Leftrightarrow \mathrm{CH}_{3} \mathrm{C}(\mathrm{O}) \mathrm{CH}_{2} \mathrm{CH}_{2} \mathrm{C}(\mathrm{O}) \dot{\mathrm{O}}+\mathrm{H}_{2} \mathrm{O}$ & $1.76 \times 10^{9}$ & 0.97 & 1,586 & Assumed to be $1 \mathrm{x}$ hydrogen abstraction from primary carbon [29]. \\
\hline $\mathrm{CH}_{3} \mathrm{C}(\mathrm{O}) \mathrm{CH}_{2} \mathrm{CH}_{2} \mathrm{C}(\mathrm{O}) \mathrm{OH}+\dot{\mathrm{O} H} \Leftrightarrow \mathrm{CH}_{3} \mathrm{C}(\mathrm{O}) \mathrm{CH}_{2} \dot{\mathrm{C}} \mathrm{HC}(\mathrm{O}) \mathrm{OH}+\mathrm{H}_{2} \mathrm{O}$ & $5.73 \times 10^{10}$ & 0.51 & 63 & Assumed to be $2 \mathrm{x}$ hydrogen abstraction from tertiary carbon [29]. \\
\hline $\mathrm{CH}_{3} \mathrm{C}(\mathrm{O}) \mathrm{CH}_{2} \mathrm{CH}_{2} \mathrm{C}(\mathrm{O}) \mathrm{OH}+\dot{\mathrm{O} H} \Leftrightarrow \mathrm{CH}_{3} \mathrm{C}(\mathrm{O}) \dot{\mathrm{C}} \mathrm{HCH}_{2} \mathrm{C}(\mathrm{O}) \mathrm{OH}+\mathrm{H}_{2} \mathrm{O}$ & $2.34 \times 10^{7}$ & 1.61 & -35 & Assumed to be $2 \mathrm{x}$ hydrogen abstraction from tertiary carbon [29]. \\
\hline $\mathrm{CH}_{3} \mathrm{C}(\mathrm{O}) \mathrm{CH}_{2} \mathrm{CH}_{2} \mathrm{C}(\mathrm{O}) \mathrm{OH}+\dot{\mathrm{O} H} \Leftrightarrow \dot{\mathrm{C}}_{2} \mathrm{C}(\mathrm{O}) \mathrm{CH}_{2} \mathrm{CH}_{2} \mathrm{C}(\mathrm{O}) \mathrm{OH}+\mathrm{H}_{2} \mathrm{O}$ & $1.76 \times 10^{9}$ & 0.95 & 1,586 & Assumed to be 3 x hydrogen abstraction from tertiary carbon [29]. \\
\hline \multicolumn{5}{|c|}{ Hydrogen Abstraction from Levulinic Acid by Methyl Radical } \\
\hline $\mathrm{CH}_{3} \mathrm{C}(\mathrm{O}) \mathrm{CH}_{2} \mathrm{CH}_{2} \mathrm{C}(\mathrm{O}) \mathrm{OH}+\dot{\mathrm{C}}_{3} \Leftrightarrow \mathrm{CH}_{3} \mathrm{C}(\mathrm{O}) \mathrm{CH}_{2} \mathrm{CH}_{2} \mathrm{C}(\mathrm{O}) \dot{\mathrm{O}}+\mathrm{CH}_{4}$ & $1.51 \times 10^{-1}$ & 3.65 & 7,154 & Assumed to be 1x hydrogen abstraction from primary carbon [29]. \\
\hline $\mathrm{CH}_{3} \mathrm{C}(\mathrm{O}) \mathrm{CH}_{2} \mathrm{CH}_{2} \mathrm{C}(\mathrm{O}) \mathrm{OH}+\dot{\mathrm{C}}_{3} \Leftrightarrow \mathrm{CH}_{3} \mathrm{C}(\mathrm{O}) \mathrm{CH}_{2} \dot{\mathrm{C}} \mathrm{HC}(\mathrm{O}) \mathrm{OH}+\mathrm{CH}_{4}$ & 1.81 & 3.46 & 4598 & Assumed to be $2 \mathrm{x}$ hydrogen abstraction from tertiary carbon [29]. \\
\hline $\mathrm{CH}_{3} \mathrm{C}(\mathrm{O}) \mathrm{CH}_{2} \mathrm{CH}_{2} \mathrm{C}(\mathrm{O}) \mathrm{OH}+\dot{\mathrm{C}}_{3} \Leftrightarrow \mathrm{CH}_{3} \mathrm{C}(\mathrm{O}) \dot{\mathrm{C}} \mathrm{HCH}_{2} \mathrm{C}(\mathrm{O}) \mathrm{OH}+\mathrm{CH}_{4}$ & 1.81 & 3.46 & 4598 & Assumed to be $2 \mathrm{x}$ hydrogen abstraction from tertiary carbon [29]. \\
\hline $\mathrm{CH}_{3} \mathrm{C}(\mathrm{O}) \mathrm{CH}_{2} \mathrm{CH}_{2} \mathrm{C}(\mathrm{O}) \mathrm{OH}+\dot{\mathrm{C}} \mathrm{H}_{3} \Leftrightarrow \dot{\mathrm{C}} \mathrm{H}_{2} \mathrm{C}(\mathrm{O}) \mathrm{CH}_{2} \mathrm{CH}_{2} \mathrm{C}(\mathrm{O}) \mathrm{OH}+\mathrm{CH}_{4}$ & 2.71 & 3.46 & 4598 & Assumed to be $3 \mathrm{x}$ hydrogen abstraction from tertiary carbon [29]. \\
\hline \multicolumn{5}{|c|}{ Hydrogen Abstraction from Levulinic Acid by Methoxy Radical } \\
\hline
\end{tabular}


$\mathrm{CH}_{3} \mathrm{C}(\mathrm{O}) \mathrm{CH}_{2} \mathrm{CH}_{2} \mathrm{C}(\mathrm{O}) \mathrm{OH}+\mathrm{CH}_{3} \mathrm{O} \Leftrightarrow \mathrm{CH}_{3} \mathrm{C}(\mathrm{O}) \mathrm{CH}_{2} \mathrm{CH}_{2} \mathrm{C}(\mathrm{O}) \dot{\mathrm{O}}+\mathrm{CH}_{3} \mathrm{OH}$ $\mathrm{CH}_{3} \mathrm{C}(\mathrm{O}) \mathrm{CH}_{2} \mathrm{CH}_{2} \mathrm{C}(\mathrm{O}) \mathrm{OH}+\mathrm{CH}_{3} \dot{\mathrm{O}} \Leftrightarrow \mathrm{CH}_{3} \mathrm{C}(\mathrm{O}) \mathrm{CH}_{2} \dot{\mathrm{C}} \mathrm{HC}(\mathrm{O}) \mathrm{OH}+\mathrm{CH}_{3} \mathrm{OH}$ $\mathrm{CH}_{3} \mathrm{C}(\mathrm{O}) \mathrm{CH}_{2} \mathrm{CH}_{2} \mathrm{C}(\mathrm{O}) \mathrm{OH}+\mathrm{CH}_{3} \dot{\mathrm{O}} \Leftrightarrow \mathrm{CH}_{3} \mathrm{C}(\mathrm{O}) \dot{\mathrm{C}} \mathrm{HCH}_{2} \mathrm{C}(\mathrm{O}) \mathrm{OH}+\mathrm{CH}_{3} \mathrm{OH}$ $\mathrm{CH}_{3} \mathrm{C}(\mathrm{O}) \mathrm{CH}_{2} \mathrm{CH}_{2} \mathrm{C}(\mathrm{O}) \mathrm{OH}+\mathrm{CH}_{3} \dot{\mathrm{O}} \Leftrightarrow \dot{\mathrm{C}} \mathrm{H}_{2} \mathrm{C}(\mathrm{O}) \mathrm{CH}_{2} \mathrm{CH}_{2} \mathrm{C}(\mathrm{O}) \mathrm{OH}+\mathrm{CH}_{3} \mathrm{OH}$ $5.33 \times 10^{10}$ $3.80 \times 10^{10}$ $3.80 \times 10^{10}$ $5.70 \times 10^{10}$

\subsection{0}

\begin{tabular}{l|l}
0.00 & 7,000 \\
\hline 0.00 & 2,800 \\
\hline
\end{tabular}

\begin{tabular}{l|l}
0.00 & 2,800 \\
\hline
\end{tabular}

\begin{tabular}{l|l}
0.00 & 2,800 \\
\hline
\end{tabular}

Hydrogen Abstraction from Levulinic

$\mathrm{CH}_{3} \mathrm{C}(\mathrm{O}) \mathrm{CH}_{2} \mathrm{CH}_{2} \mathrm{C}(\mathrm{O}) \mathrm{OH}+\mathrm{CH}_{3} \dot{\mathrm{O}}_{2} \Leftrightarrow \mathrm{CH}_{3} \mathrm{C}(\mathrm{O}) \mathrm{CH}_{2} \mathrm{CH}_{2} \mathrm{C}(\mathrm{O}) \dot{\mathrm{O}}+\mathrm{CH}_{3} \mathrm{O}_{2} \mathrm{H}$

$\mathrm{CH}_{3} \mathrm{C}(\mathrm{O}) \mathrm{CH}_{2} \mathrm{CH}_{2} \mathrm{C}(\mathrm{O}) \mathrm{OH}+\mathrm{CH}_{3} \dot{\mathrm{O}}_{2} \Leftrightarrow \mathrm{CH}_{3} \mathrm{C}(\mathrm{O}) \mathrm{CH}_{2} \dot{\mathrm{C}} \mathrm{HC}(\mathrm{O}) \mathrm{OH}+\mathrm{CH}_{3} \mathrm{O}_{2} \mathrm{H}$

$\mathrm{CH}_{3} \mathrm{C}(\mathrm{O}) \mathrm{CH}_{2} \mathrm{CH}_{2} \mathrm{C}(\mathrm{O}) \mathrm{OH}+\mathrm{CH}_{3} \dot{\mathrm{O}}_{2} \Leftrightarrow \mathrm{CH}_{3} \mathrm{C}(\mathrm{O}) \dot{\mathrm{C}} \mathrm{HCH}_{2} \mathrm{C}(\mathrm{O}) \mathrm{OH}+\mathrm{CH}_{3} \mathrm{O}_{2} \mathrm{H}$

Acid by

8,280 Assumed to

Assumed to be 1x hydrogen abstraction from primary carbon [29].

Assumed to be $2 x$ hydrogen abstraction from tertiary carbon [29].

Assumed to be $2 \mathrm{x}$ hydrogen abstraction from tertiary carbon [29].

Assumed to be $3 \mathrm{x}$ hydrogen abstraction from tertiary carbon [29].

$\mathrm{CH}_{3} \mathrm{C}(\mathrm{O}) \mathrm{CH}_{2} \mathrm{CH}_{2} \mathrm{C}(\mathrm{O}) \mathrm{OH}+\mathrm{CH}_{3} \dot{\mathrm{O}}_{2} \Leftrightarrow \dot{\mathrm{CH}}_{2} \mathrm{C}(\mathrm{O}) \mathrm{CH}_{2} \mathrm{CH}_{2} \mathrm{C}(\mathrm{O}) \mathrm{OH}+\mathrm{CH}_{3} \mathrm{O}_{2} \mathrm{H}$

$\mathrm{CH}_{3} \mathrm{C}(\mathrm{O}) \mathrm{CH}_{2} \mathrm{CH}_{2} \mathrm{C}(\mathrm{O}) \mathrm{OH}+\mathrm{HO}_{2} \Leftrightarrow \mathrm{CH}_{3} \mathrm{C}(\mathrm{O}) \mathrm{CH}_{2} \mathrm{CH}_{2} \mathrm{C}(\mathrm{O}) \dot{\mathrm{O}}+\mathrm{H}_{2} \mathrm{O}_{2}$

$\mathrm{CH}_{3} \mathrm{C}(\mathrm{O}) \mathrm{CH}_{2} \mathrm{CH}_{2} \mathrm{C}(\mathrm{O}) \mathrm{OH}+\mathrm{HO}_{2} \Leftrightarrow \mathrm{CH}_{3} \mathrm{C}(\mathrm{O}) \mathrm{CH}_{2} \dot{\mathrm{C}} \mathrm{HC}(\mathrm{O}) \mathrm{OH}+\mathrm{H}_{2} \mathrm{O}_{2}$

$\mathrm{CH}_{3} \mathrm{C}(\mathrm{O}) \mathrm{CH}_{2} \mathrm{CH}_{2} \mathrm{C}(\mathrm{O}) \mathrm{OH}+\mathrm{HO}_{2} \Leftrightarrow \mathrm{CH}_{3} \mathrm{C}(\mathrm{O}) \dot{\mathrm{C}} \mathrm{HCH}_{2} \mathrm{C}(\mathrm{O}) \mathrm{OH}+\mathrm{H}_{2} \mathrm{O}_{2}$

$\mathrm{CH}_{3} \mathrm{C}(\mathrm{O}) \mathrm{CH}_{2} \mathrm{CH}_{2} \mathrm{C}(\mathrm{O}) \mathrm{OH}+\mathrm{HO}_{2} \Leftrightarrow \dot{\mathrm{C}} \mathrm{H}_{2} \mathrm{C}(\mathrm{O}) \mathrm{CH}_{2} \mathrm{CH}_{2} \mathrm{C}(\mathrm{O}) \mathrm{OH}+\mathrm{H}_{2} \mathrm{O}_{2}$

$2.31 \times 10^{-1}$

$2.73 \times 10^{02}$

$2.73 \times 10^{02}$

$4.10 \times 10^{02}$

\begin{tabular}{l|l}
3.97 & 18,280 \\
3.12 & 13,190
\end{tabular}

Hydrogen Abstraction from Levulini

$6.80 \times 10^{0}-3.59$

13,190

13,190

13,190

to be $1 x$ hydrogen abstraction from primary carbon [29].

Assumed to be $2 \mathrm{x}$ hydrogen abstraction from tertiary carbon [29]. Assumed to be $2 \times$ hydrogen abstraction from tertiary carbon [29]. Assumed to be $3 \times$ hydrogen abstraction from tertiary carbon [29].

\begin{tabular}{|l|l}
$6.80 \times 10^{0}$ & 3.5 \\
\hline $8.66 \times 10^{2}$ & 3.0 \\
\hline $8.66 \times 10^{2}$ & 3.0 \\
\hline $1.30 \times 10^{3}$ & 3.0
\end{tabular}

Hydrogen Abstraction from $L$

$\mathrm{CH}_{3} \mathrm{C}(\mathrm{O}) \mathrm{CH}_{2} \mathrm{CH}_{2} \mathrm{C}(\mathrm{O}) \mathrm{OH}+\ddot{\mathrm{O}} \Leftrightarrow \mathrm{CH}_{3} \mathrm{C}(\mathrm{O}) \mathrm{CH}_{2} \mathrm{CH}_{2} \mathrm{C}(\mathrm{O}) \dot{\mathrm{O}}+\dot{\mathrm{O}}$

$\mathrm{CH}_{3} \mathrm{C}(\mathrm{O}) \mathrm{CH}_{2} \mathrm{CH}_{2} \mathrm{C}(\mathrm{O}) \mathrm{OH}+\ddot{\mathrm{O}} \Leftrightarrow \mathrm{CH}_{3} \mathrm{C}(\mathrm{O}) \mathrm{CH}_{2} \dot{\mathrm{CHC}}(\mathrm{O}) \mathrm{OH}+\dot{\mathrm{OH}}$

$\mathrm{CH}_{3} \mathrm{C}(\mathrm{O}) \mathrm{CH}_{2} \mathrm{CH}_{2} \mathrm{C}(\mathrm{O}) \mathrm{OH}+\ddot{\mathrm{O}} \Leftrightarrow \mathrm{CH}_{3} \mathrm{C}(\mathrm{O}) \dot{\mathrm{C}} \mathrm{HCH}_{2} \mathrm{C}(\mathrm{O}) \mathrm{OH}+\dot{\mathrm{OH}}$

$\mathrm{CH}_{3} \mathrm{C}(\mathrm{O}) \mathrm{CH}_{2} \mathrm{CH}_{2} \mathrm{C}(\mathrm{O}) \mathrm{OH}+\ddot{\mathrm{O}} \Leftrightarrow \dot{\mathrm{C}} \mathrm{H}_{2} \mathrm{C}(\mathrm{O}) \mathrm{CH}_{2} \mathrm{CH}_{2} \mathrm{C}(\mathrm{O}) \mathrm{OH}+\dot{\mathrm{OH}}$

Hydrogen Abs

Levulinic Acid by Oxygen Atom

$\mathrm{CH}_{3} \mathrm{C}(\mathrm{O}) \mathrm{CH}_{2} \mathrm{CH}_{2} \mathrm{C}(\mathrm{O}) \mathrm{OH}+\mathrm{O}_{2} \Leftrightarrow \mathrm{CH}_{3} \mathrm{C}(\mathrm{O}) \mathrm{CH}_{2} \mathrm{CH}_{2} \mathrm{C}(\mathrm{O}) \dot{\mathrm{O}}+\mathrm{HO}$

$\mathrm{CH}_{3} \mathrm{C}(\mathrm{O}) \mathrm{CH}_{2} \mathrm{CH}_{2} \mathrm{C}(\mathrm{O}) \mathrm{OH}+\mathrm{O}_{2} \Leftrightarrow \mathrm{CH}_{3} \mathrm{C}(\mathrm{O}) \mathrm{CH}_{2} \dot{\mathrm{C}} \mathrm{HC}(\mathrm{O}) \mathrm{OH}+\mathrm{HO}_{2}$

$\mathrm{CH}_{3} \mathrm{C}(\mathrm{O}) \mathrm{CH}_{2} \mathrm{CH}_{2} \mathrm{C}(\mathrm{O}) \mathrm{OH}+\mathrm{O}_{2} \Leftrightarrow \mathrm{CH}_{3} \mathrm{C}(\mathrm{O}) \dot{\mathrm{C}} \mathrm{HCH}_{2} \mathrm{C}(\mathrm{O}) \mathrm{OH}+\mathrm{HO}_{2}$

$\mathrm{CH}_{3} \mathrm{C}(\mathrm{O}) \mathrm{CH}_{2} \mathrm{CH}_{2} \mathrm{C}(\mathrm{O}) \mathrm{OH}+\mathrm{O}_{2} \Leftrightarrow \dot{\mathrm{C}} \mathrm{H}_{2} \mathrm{C}(\mathrm{O}) \mathrm{CH}_{2} \mathrm{CH}_{2} \mathrm{C}(\mathrm{O}) \mathrm{OH}+\mathrm{HO}_{2}$

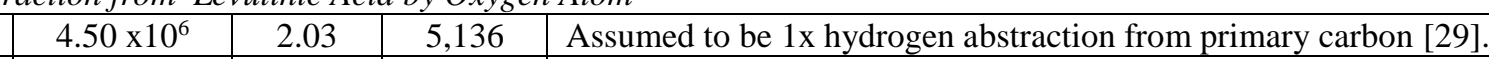

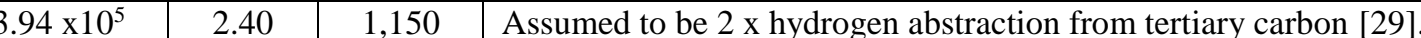

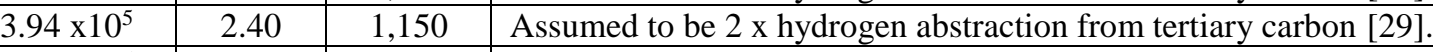

$5.90 \times 10^{5}$

2.40

1,150

Assumed to be $3 \mathrm{x}$ hydrogen abstraction from tertiary carbon [29].

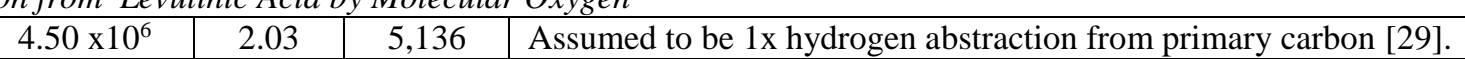

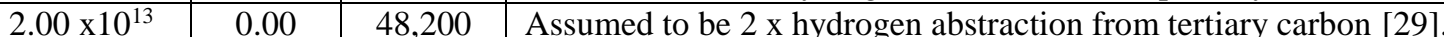

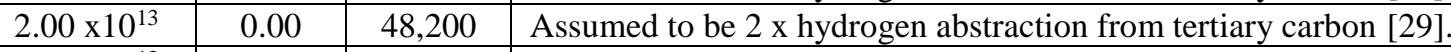

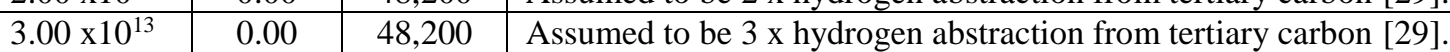

Levulinic Acid Alkyl Radical Beta-bond Scission

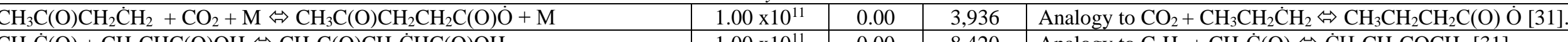

$\mathrm{CH}_{3} \dot{\mathrm{C}}(\mathrm{O})+\mathrm{CH}_{2} \mathrm{CHC}(\mathrm{O}) \mathrm{OH} \Leftrightarrow \mathrm{CH}_{3} \mathrm{C}(\mathrm{O}) \mathrm{CH}_{2} \dot{\mathrm{C}} \mathrm{HC}(\mathrm{O}) \mathrm{OH}$

$\mathrm{CH}_{3} \mathrm{C}(\mathrm{O}) \mathrm{CH}_{2} \mathrm{CHC}(\mathrm{O})+\dot{\mathrm{OH}} \Leftrightarrow \mathrm{CH}_{3} \mathrm{C}(\mathrm{O}) \mathrm{CH}_{2} \dot{\mathrm{CHC}}(\mathrm{O}) \mathrm{OH}$

$\mathrm{CH}_{3} \mathrm{C}(\mathrm{O}) \mathrm{CHCH}_{2}+\dot{\mathrm{C}}(\mathrm{O}) \mathrm{OH} \Leftrightarrow \mathrm{CH}_{3} \mathrm{C}(\mathrm{O}) \dot{\mathrm{C}} \mathrm{HCH}_{2} \mathrm{C}(\mathrm{O}) \mathrm{OH}$

$\dot{\mathrm{C}} \mathrm{H}_{3}+\mathrm{C}(\mathrm{O}) \mathrm{CHCH}_{2} \mathrm{C}(\mathrm{O}) \mathrm{OH} \Leftrightarrow \mathrm{CH}_{3} \mathrm{C}(\mathrm{O}) \dot{\mathrm{C}} \mathrm{HCH}_{2} \mathrm{C}(\mathrm{O}) \mathrm{OH}$

$\dot{\mathrm{C}} \mathrm{H}_{3}+\mathrm{C}(\mathrm{O}) \mathrm{CHCH}_{2} \mathrm{C}(\mathrm{O}) \mathrm{OH} \Leftrightarrow \dot{\mathrm{C}} \mathrm{H}_{2} \mathrm{C}(\mathrm{O}) \mathrm{CH}_{2} \mathrm{CH}_{2} \mathrm{C}(\mathrm{O}) \mathrm{OH}$

$\mathrm{CH}_{2} \mathrm{C}(\mathrm{O})+\dot{\mathrm{C}} \mathrm{H}_{2} \mathrm{CH}_{2} \mathrm{C}(\mathrm{O}) \mathrm{OH} \Leftrightarrow \dot{\mathrm{C}} \mathrm{H}_{2} \mathrm{C}(\mathrm{O}) \mathrm{CH}_{2} \mathrm{CH}_{2} \mathrm{C}(\mathrm{O}) \mathrm{OH}$

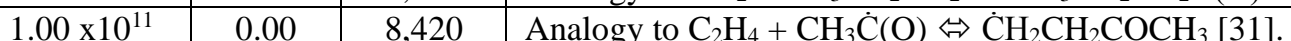

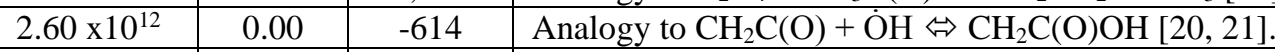

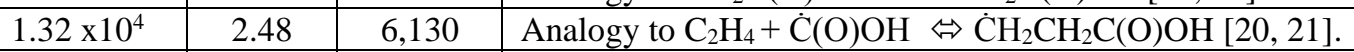

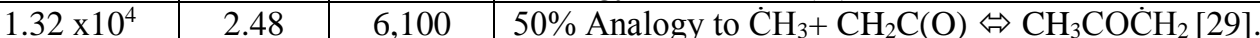

\begin{tabular}{lll|l}
$1.00 \times 10^{11}$ & 0.00 & 6300 & Analagy to $\mathrm{CH} 3 \mathrm{COCH} 2=\mathrm{CH} 2 \mathrm{CO}+\mathrm{CH} 3[29]$.
\end{tabular}

Levulinic Acid Alkyl and Alkoxy Radical Isomerisations
L

$\mathrm{CH}_{3} \mathrm{C}(\mathrm{O}) \mathrm{CH}_{2} \mathrm{CH}_{2} \mathrm{C}(\mathrm{O}) \dot{\mathrm{O}} \Leftrightarrow \mathrm{CH}_{3} \mathrm{C}(\mathrm{O}) \mathrm{CH}_{2} \dot{\mathrm{C}} \mathrm{HC}(\mathrm{O}) \mathrm{OH}$

$\mathrm{CH}_{3} \mathrm{C}(\mathrm{O}) \mathrm{CH}_{2} \mathrm{CH}_{2} \mathrm{C}(\mathrm{O}) \dot{\mathrm{O}} \Leftrightarrow \mathrm{CH}_{3} \mathrm{C}(\mathrm{O}) \dot{\mathrm{C}} \mathrm{HCH}_{2} \mathrm{C}(\mathrm{O}) \mathrm{OH}$

$\mathrm{CH}_{3} \mathrm{C}(\mathrm{O}) \mathrm{CH}_{2} \mathrm{CH}_{2} \mathrm{C}(\mathrm{O}) \dot{\mathrm{O}} \Leftrightarrow \dot{\mathrm{C}} \mathrm{H}_{2} \mathrm{C}(\mathrm{O}) \mathrm{CH}_{2} \mathrm{CH}_{2} \mathrm{C}(\mathrm{O}) \mathrm{OH}$

$\mathrm{CH}_{3} \mathrm{C}(\mathrm{O}) \mathrm{CH}_{2} \dot{\mathrm{C}} \mathrm{HC}(\mathrm{O}) \mathrm{OH} \Leftrightarrow \mathrm{CH}_{3} \mathrm{C}(\mathrm{O}) \dot{\mathrm{C}} \mathrm{HCH}_{2} \mathrm{C}(\mathrm{O}) \mathrm{OH}$

\begin{tabular}{|c|c|c|l|}
\hline $1.00 \times 10^{13}$ & 0.00 & 0.0 & Assumed to be in thermodynamic equilibrium [32]. \\
\hline $1.00 \times 10^{13}$ & 0.00 & 0.0 & Assumed to be in thermodynamic equilibrium [32]. \\
\hline $1.00 \times 10^{13}$ & 0.00 & 0.0 & Assumed to be in thermodynamic equilibrium [32]. \\
\hline $1.00 \times 10^{13}$ & 0.00 & 0.0 & Assumed to be in thermodynamic equilibrium [32]. \\
\hline
\end{tabular}




\begin{tabular}{|c|c|c|c|c|}
\hline $\mathrm{CH}_{3} \mathrm{C}(\mathrm{O}) \mathrm{CH}_{2} \dot{\mathrm{C}} \mathrm{HC}(\mathrm{O}) \mathrm{OH} \Leftrightarrow \dot{\mathrm{C}} \mathrm{H}_{2} \mathrm{C}(\mathrm{O}) \mathrm{CH}_{2} \mathrm{CH}_{2} \mathrm{C}(\mathrm{O}) \mathrm{OH}$ & $1.00 \times 10^{13}$ & 0.00 & 0.0 & Assumed to be in thermodynamic equilibrium [32]. \\
\hline $\mathrm{CH}_{3} \mathrm{C}(\mathrm{O}) \dot{\mathrm{C}} \mathrm{HCH}_{2} \mathrm{C}(\mathrm{O}) \mathrm{OH} \Leftrightarrow \dot{\mathrm{C}} \mathrm{H}_{2} \mathrm{C}(\mathrm{O}) \mathrm{CH}_{2} \mathrm{CH}_{2} \mathrm{C}(\mathrm{O}) \mathrm{OH}$ & $1.00 \times 10^{13}$ & 0.00 & 0.0 & Assumed to be in thermodynamic equilibrium [32]. \\
\hline \multicolumn{5}{|c|}{ Ethyl Propanoate Submodel } \\
\hline$\dot{\mathrm{C}} \mathrm{H}_{2} \mathrm{CH}_{2} \mathrm{C}(\mathrm{O}) \mathrm{OCH}_{2} \mathrm{CH}_{3} \Leftrightarrow \mathrm{C}_{2} \mathrm{H}_{4}+\mathrm{CH}_{3} \mathrm{CH}_{2} \mathrm{OC}(\mathrm{O})$ & $8.827 \times 10^{15}$ & -0.67 & 35,550 & Adopted from ethyl propanoate $[20,21]$. \\
\hline $\mathrm{CH}_{3} \mathrm{CH}_{2} \mathrm{OC}(\mathrm{O})+\mathrm{M} \Leftrightarrow \mathrm{CH}_{3} \mathrm{CH}_{2} \mathrm{O}+\mathrm{CO}+\mathrm{M}$ & $5.059 \times 10^{14}$ & 0.17 & 25,520 & Adopted from ethyl propanoate $[20,21]$. \\
\hline $\mathrm{CH}_{3} \mathrm{CH}_{2} \mathrm{OC}(\mathrm{O})+\mathrm{M} \Leftrightarrow \mathrm{CH}_{3} \dot{\mathrm{C}} \mathrm{H}_{2}+\mathrm{CO}_{2}+\mathrm{M}$ & $4.400 \times 10^{15}$ & 0.0 & 1,0500 & Adopted from ethyl propanoate $[20,21]$. \\
\hline $\mathrm{CH}_{3} \mathrm{CH}_{2} \mathrm{C}(\mathrm{O}) \mathrm{OC}_{2} \Leftrightarrow \mathrm{CH}_{2} \mathrm{O}+\mathrm{CH}_{3} \mathrm{CH}_{2} \dot{\mathrm{C}}(\mathrm{O})$ & $7.949 \times 10^{20}$ & -1.82 & 4,4530 & Adopted from methyl butanoate $[20,21]$. \\
\hline $\mathrm{CH}_{2} \mathrm{CHC}(\mathrm{O}) \mathrm{OC}^{-} \mathrm{H}_{2} \Leftrightarrow \mathrm{CH}_{2} \mathrm{O}+\mathrm{CH}_{2} \mathrm{CHC}(\mathrm{O})$ & $2.418 \times 10^{23}$ & -2.82 & 36,410 & Adopted from methyl butanoate $[20,21]$. \\
\hline$\dot{\mathrm{C}} \mathrm{H}_{2} \mathrm{C}(\mathrm{O}) \mathrm{OCH}_{2} \mathrm{CH}_{3} \Leftrightarrow \mathrm{CH}_{2} \mathrm{CO}+\mathrm{CH}_{3} \mathrm{CH}_{2} \dot{\mathrm{O}}$ & $9.364 \times 10^{19}$ & -1.88 & 56,420 & Adopted from ethyl propanoate $[20,21]$. \\
\hline $\mathrm{CO}+\dot{\mathrm{C}} \mathrm{H}_{2} \mathrm{CH}_{2} \mathrm{C}(\mathrm{O}) \mathrm{OH}+\mathrm{M} \Leftrightarrow \dot{\mathrm{C}}(\mathrm{O}) \mathrm{CH}_{2} \mathrm{CH}_{2} \mathrm{C}(\mathrm{O}) \mathrm{OH}+\mathrm{M}$ & $1.510 \times 10^{11}$ & 0.00 & 4,810 & Adopted from ethyl propanoate $[20,21]$. \\
\hline$\dot{\mathrm{C}} \mathrm{H}_{2} \mathrm{CH}_{2} \mathrm{C}(\mathrm{O}) \mathrm{OH} \Leftrightarrow \mathrm{C}_{2} \mathrm{H}_{4}+\dot{\mathrm{C}}(\mathrm{O}) \mathrm{OH}$ & $4.217 \times 10^{14}$ & -0.32 & 3486 & Adopted from ethyl propanoate $[20,21]$. \\
\hline$\dot{\mathrm{C}} \mathrm{H}_{2} \mathrm{C}(\mathrm{O}) \mathrm{OH} \Leftrightarrow \mathrm{CH}_{2} \mathrm{CO}+\dot{\mathrm{O} H}$ & $4.638 \times 10^{18}$ & -1.28 & 5386 & Adopted from ethyl propanoate $[20,21]$. \\
\hline \multicolumn{5}{|c|}{ Acrylic Acid Submodel } \\
\hline $\mathrm{CH}_{2} \mathrm{CHC}(\mathrm{O}) \mathrm{OH} \Leftrightarrow \mathrm{CH}_{2} \dot{\mathrm{C}} \mathrm{H}+\dot{\mathrm{C}}(\mathrm{O}) \mathrm{OH}$ & $3.752 \times 10^{21}$ & -1.89 & 112,900 & Adopted from ethyl propanoate $[20,21]$. \\
\hline $\mathrm{CH}_{2} \mathrm{CHC}(\mathrm{O}) \mathrm{OH} \Leftrightarrow \mathrm{CH}_{2} \mathrm{CHC}(\mathrm{O})+\dot{\mathrm{O} H}$ & $5.206 \times 10^{20}$ & -1.16 & 100,900 & Adopted from ethyl propanoate $[20,21]$. \\
\hline $\mathrm{CH}_{2} \mathrm{CHC}(\mathrm{O})+\dot{\mathrm{OH}} \Leftrightarrow \mathrm{C}_{2} \mathrm{H}_{4}+\mathrm{CO}_{2}$ & $1.000 \times 10^{12}$ & 0.00 & 0 & Adopted from ethyl propanoate $[20,21]$. \\
\hline $\mathrm{CH}_{2} \mathrm{CHC}(\mathrm{O})+\mathrm{HO}_{2} \Leftrightarrow \mathrm{CH}_{2} \dot{\mathrm{C}} \mathrm{H}+\mathrm{CO}_{2}+\dot{\mathrm{O}} \mathrm{H}$ & $6.030 \times 10^{9}$ & 0.00 & 7,949 & Adopted from ethyl propanoate $[20,21]$. \\
\hline $\mathrm{CH}_{2} \mathrm{CHC}(\mathrm{O})+\mathrm{CH} 3 \dot{\mathrm{O}}_{2} \Leftrightarrow \mathrm{CH}_{2} \dot{\mathrm{C}} \mathrm{H}+\mathrm{CO}_{2}+\mathrm{CH}_{3} \dot{\mathrm{O}}$ & $3.970 \times 10^{11}$ & 0.00 & 17,050 & Adopted from ethyl propanoate $[20,21]$. \\
\hline$\dot{\mathrm{C}}(\mathrm{O}) \mathrm{OH}+\mathrm{M} \Leftrightarrow \mathrm{CO}+\dot{\mathrm{O} H}+\mathrm{M}$ & $1.186 \times 10^{14}$ & 0.13 & 36,460 & Adopted from ethyl propanoate $[20,21]$. \\
\hline$\dot{\mathrm{C}}(\mathrm{O}) \mathrm{OH}+\mathrm{M} \Leftrightarrow \mathrm{CO}_{2}+\mathrm{H}+\mathrm{M}$ & $8.220 \times 10^{11}$ & 0.41 & 35,340 & Adopted from ethyl propanoate $[20,21]$. \\
\hline
\end{tabular}

Table 4. Reaction pathways, estimated rate constants and sources for the reactions of the ethyl levulinate sub model. Rate coefficients are in the form $k=A T^{n} \exp \left(-E_{a} / R T\right), \mathrm{cm} 3 / \mathrm{mole} / \mathrm{s}$. Activation energies are in calories $/ \mathrm{mol}$. 


\subsection{Submodels, Small Species Chemistry and Model Calculations}

A purpose of the kinetic model is to aid in the comprehension of the use of this potential biofuel when blended with conventional fuels, such as gasoline. To allow for this pursuit, the ethyl levulinate chemistry is added to the primary/toluene reference fuel kinetic model of Mehl et al. [33], therefore assuming the validity of that state of the art construct.

The modelling computations in this study are carried out using the closed homogeneous (senkin) subroutine of ChemkinPro. The fundamental modelling assumptions used in comparing the purely chemical kinetic calculations with experiments are as follows; shock tube simulations are zero dimensional and begin at the onset of the reflected shock period assuming constant volume and homogeneous adiabatic conditions behind the reflected shock wave and consistent with the experimentally observed pressure profiles. The reflected shock pressure and temperature are inputted as the initial pressure and temperature, respectively. The simulated ignition delay time is defined as per the experiment. The volume history approach was used to describe the compression and heat loss of behaviours of the RCM device. The kinetic model, all pertinent experimental data, including volume histories are available in supplementary materials.

\section{Results and Discussion}

\subsection{Ethyl Levulinate Ignition Delay}

The ignition delay data for ethyl levulinate is compared to model simulations in Figure 6. The shock tube data, 1100-1400 K, is characterised by the normal Arrhenius like temperature dependence, and increase in reactivity with increased oxygen concentration. The RCM data behaves similarly, and is seemingly consistent with the shock tube data, showing longer ignition delays due to the dynamic temperature characteristic of that device, resulting in an apparent change in activation energy. The truncated temperature range in which ethyl levulinate is reactive is notable, showing no ignition at temperatures lower than $\sim 1040 \mathrm{~K}$. Though the ignition quality tester data of Tian et al. [14] is of a very different, multiphase, higher fuel concentration, variable equivalence ratio nature, relative to our 
$\mathrm{RCM}$ tests, it is perhaps worth to note that the ignition quality tester measured ignition delay is in apparent qualitative agreement with the RCM measured ignition delays ranging from $100-700 \mathrm{~ms}$ over a temperature range of $900-700 \mathrm{~K}$. The kinetic model reproduces the shock tube measured reactivity rather closely, to with a maximum deviation of $\pm 30 \%$, accurately capturing the reactivity dependence on temperature and oxygen concentration. Figure 6 shows that the modelling protocol reproduces the RCM ignition times to a lesser fidelity. Considering the weak energy density of the mixtures studied and the dynamic temperature environment of the RCM, we believe that the physical models assumed in the simulations more adequately approximate the conditions generated by the shock tube, than those of the RCM. It is known that low energy density, low pressure compressed states show a greater propensity to form cool boundary layers in the RCM [15], exacerbating undesired fluid dynamic perturbations to the intended adiabatic core gas. In Figure 6, the constant volume model calculations are extended to the temperatures of the RCM measurements and provide an easier reference for gauging the reactivity of ethyl levulinate at low temperatures. The model shows ethyl levulinate to exhibit Arrhenius type dependence across the studied temperature range, though not shown in Figure 6 for clarity, ceasing to ignite at time scales lower than $500 \mathrm{~ms}$ between 800-700 K. We emphasize that the model inputs have not been adjusted from the "best knowledge" estimates described above, to better reproduce one data set over the other. This being the case, the modelling methodology demonstrates the applicability of the functionality concept in kinetic modelling, and the accuracy of the underpinning thermochemistry study and prior kinetic modelling studies of other embodiments of the functionalities that comprise ethyl levulinate, e.g. $[4,5,19-22$, 24-28, 33]. 


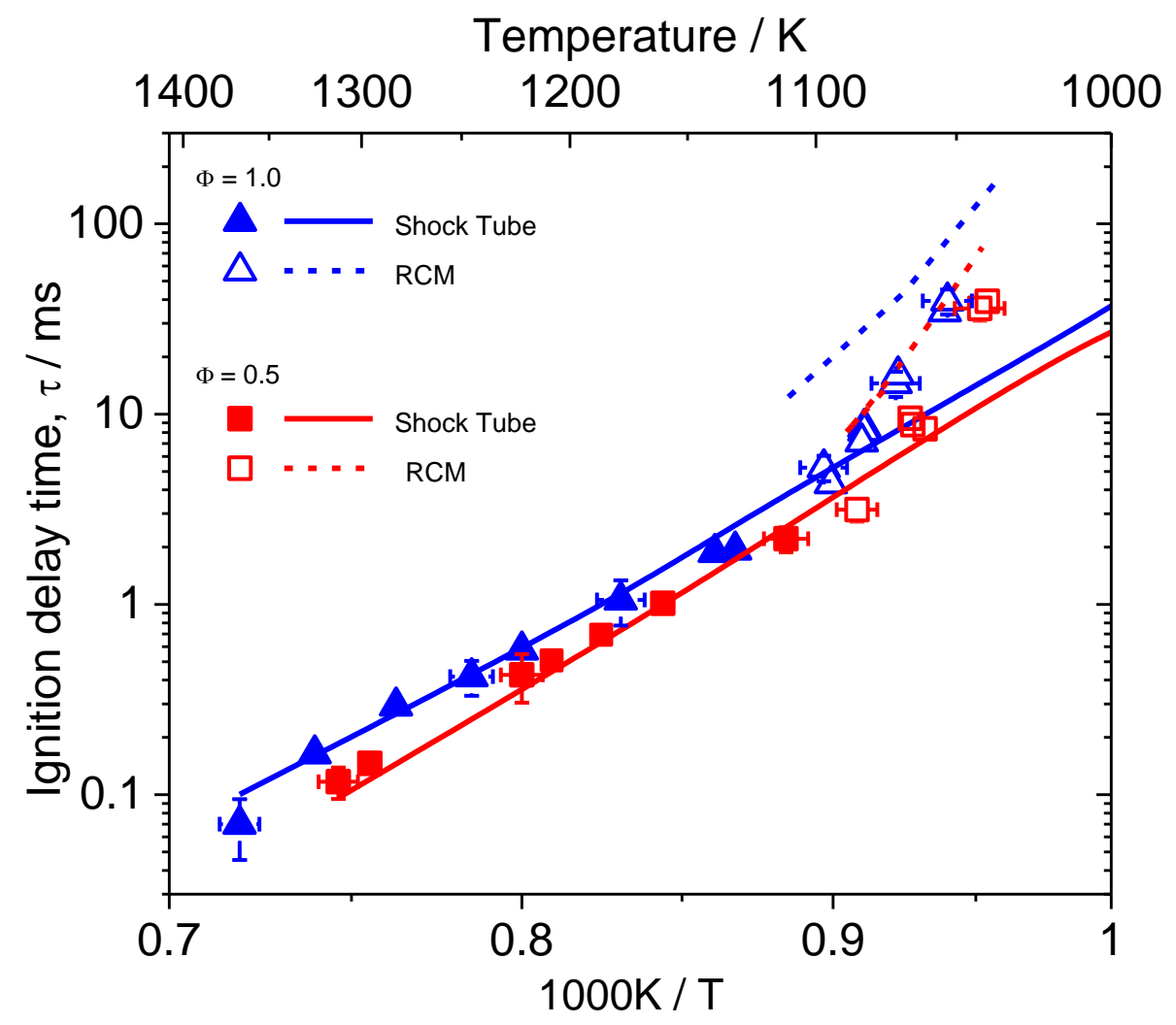

Figure 6. Shock tube and rapid compression machine ignition delay times for $0.5 \%$ ethyl levulinate, $\phi$ 1.0 and $\phi 0.5$, at $\sim 10 \mathrm{~atm}$.

\subsection{Kinetic Model Analysis}

Chemical flux and sensitivity analyses of a $0.5 \%$ ethyl levulinate oxidation at $1250 \mathrm{~K}$ and $10.4 \mathrm{~atm}$ for the stoichiometric mixture are presented in Figure 7 and 8 respectively, as representative of the range of test conditions studied. The flux analysis paints a simple picture of ethyl levulinate oxidation under induction conditions, showing that almost $96 \%$ of the ethyl levulinate fuel decomposes to levulinic acid and ethylene as molecular products. Approximately $2.6 \%$ of the fuel undergoes simple fission of the weaker $\mathrm{C}-\mathrm{C}$ and $\mathrm{C}-\mathrm{O}$ bonds, leaving only minute quantities of ethyl levulinate to be consumed by hydrogen abstraction reactions. This analysis would therefore indicate that the uncertainty in the prescription of rate constants to the unusually weak $\mathrm{C}-\mathrm{H}$ bonds, is not an especially corrupting uncertainty to the model overall. This simplistic oxidation behavior is in notable contrast to what has been reported many times for alkanes and other oxygenates, where hydrogen abstraction and alkyl radical beta bond scission are commanding processes. The simplicity of the ethyl 
levulinate oxidation mechanism is thus notable, but completely consistent with the suggestions of other workers concerning other ethyl esters $[20,21,26-28,34,35]$ and indeed basically verifying the assumptions made by Tian et al. [14] in attempting to explain the engine reactivity and ignition delay of ethyl levuliante. 


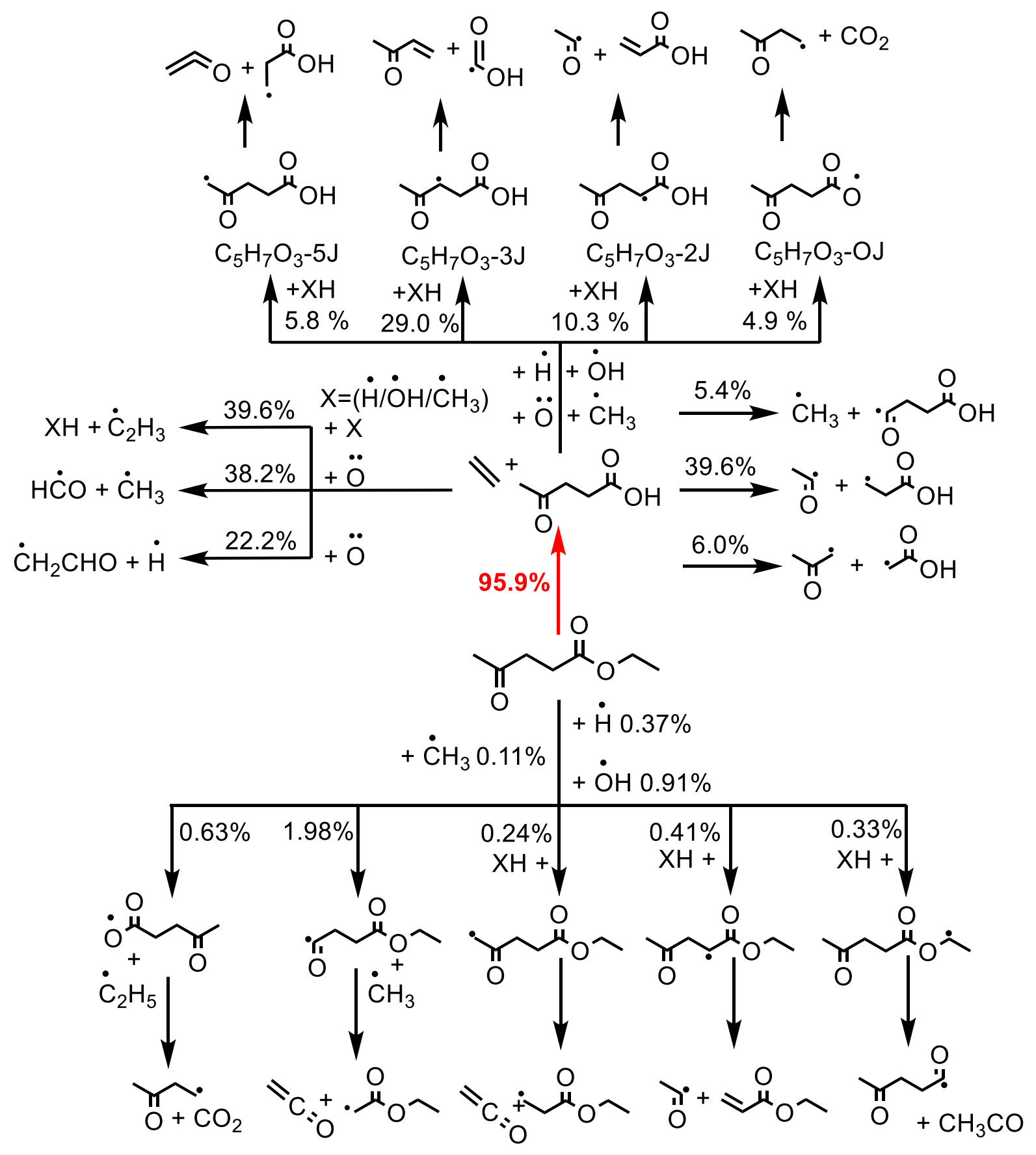

Figure 7. Reacting flux analysis at the point of 50\% ethyl levulinate consumption for shock tube simulation of $0.5 \%$ fuel, $\phi 1.0$ at 10.4 atm and $1250 \mathrm{~K}$. 


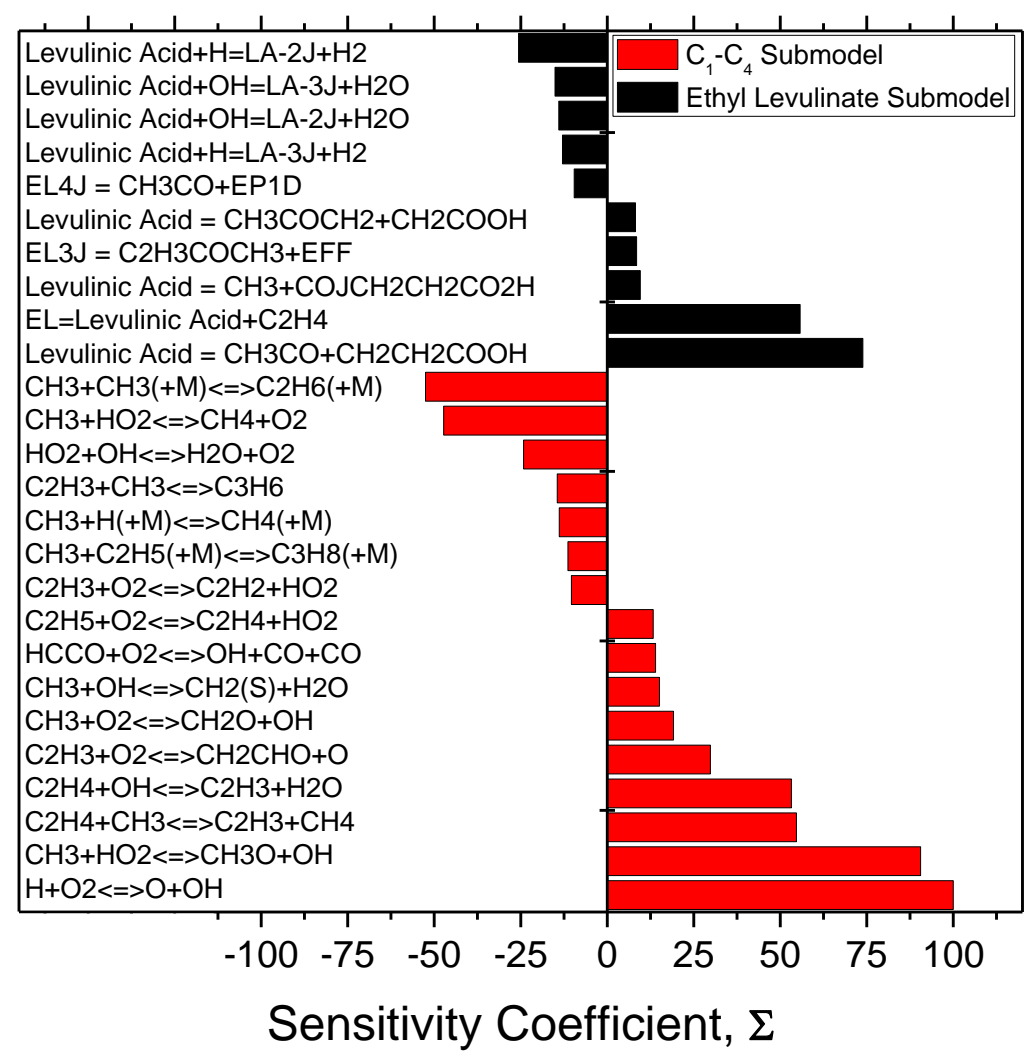

Figure 8 . Sensitivity analysis to $\Delta \mathrm{T}$ in ethyl levulinate shock tube ignition delay simulation for $0.5 \%$ fuel, $\phi 1.0$ at 10.4 atm and $1250 \mathrm{~K}$. "LA-"X"J" designates levulinic acid radicals per Figure 7.

Figure 8 shows a sensitivity analysis of the reactions effecting $\Delta \mathrm{T}$, the analyses is divided into reactions of the ethyl levulinate submodel and to reactions of the small species chemistry. A positive value indicates that a reaction increases the temperature of the system, leading to ignition. As expected, the most sensitive reaction at this $1250 \mathrm{~K}$ condition is the $\mathrm{H}+\mathrm{O}_{2} \Leftrightarrow \mathrm{O}+\mathrm{OH}$, the magnitude of all sensitivity coefficients have been normalized to this reference. An arbitrary threshold of $10 \%$ of this value has been imposed for a reaction to be included in Figure 8. The analysis shows the ethyl levulinate submodel to be dominated by the chemistry accounting for levulinic acid production and consumption. The ethyl levulinate elimination reaction is the fourth most sensitive reaction in the system, with the further unimolecular decomposition of levulinic acid to produce two radicals the most reactivity enhancing reaction in the ethyl levulinate submodel. For this reason, the occurrence of 
hydrogen abstraction reactions that consume either ethyl levulinate, or levulinic acid, produce a negative effect on the reactivity of the system. Examination of the role of the chemistry of the submodel reveals the influence of ethylene, the co-product to levulinic acid formation. The vinyl radical is formed by hydrogen abstraction from ethylene and subsequently consumed by addition of $\mathrm{O}_{2}$, Figure 8. Reactions which produce the vinyl radical show a strong positive influence on the reaction rate, as it is predominantly consumed by reaction with $\mathrm{O}_{2}$ to form radical chain branching products of $\mathrm{CH}_{2} \mathrm{CHO}+\mathrm{O}$. From the above analysis, the importance of the levulinic acid oxidation mechanism to the combustion of ethyl levulinate is clearly apparent. It should be noted that levulinic acid combustion has never been exclusively studied. If ethyl levulinate does find eventual commercial use as a transportation fuel component, a more detailed understanding of its combustion mechanism may be required, at that time the levulinic acid submodel may be worthy of dedicated attention.

\subsection{Ethyl Levulinate Octane Number Calculation}

With an accurate kinetic model for ethyl levulinate and ternary reference fuel combustion, the research octane number $(\mathrm{RON})$ and the motor octane number (MON) of ethyl levulinate can be estimated using the relationship proposed by Singh et al. [36], which correlates model calculated ignition delay time to the RON ("IDT to RON") and to the MON ("IDT to MON") of the fuel. Singh et al. developed the two models using a double exponential equation to describe the relationship between the ignition delay time and the octane number of the form:

$$
x O N=a+\left(b \cdot \exp ^{(-I D T / c)}\right)+\left(d \cdot \exp ^{(-I D T / e)}\right)
$$

Where $x O N$ can either be RON or MON, IDT refers to the ignition delay time and $a, b, c, d$ and $e$ are the model parameters which are determined by the minimization of errors between the measured and predicted (simulated) values.

The ignition delay times used by Singh et al. to develop the IDT-to-RON and IDT-to-MON models were calculated using a different chemical kinetic model than the one used in this work. Thus, for better accuracy, the parameters $(a-e)$ derived by Singh et al., for both the IDT-to-RON and IDTto-MON models, were re-estimated using ignition delay times calculated by the model constructed in 
this study. For the re-estimation of the model parameters in the IDT-to-RON model, ignition delay times were calculated for the reference fuel blends, outlined in Table S2, at a temperature of $750 \mathrm{~K}$, a pressure of 25 bar and equivalence ratio of 1 , and for the IDT-to-MON model at a temperature of 825 $\mathrm{K}$, pressure of 25 bar and equivalence ratio of 1, as Singh et al. noted these conditions resulted in the best correlation between the ignition delay time and the respective octane number. Values calculated for the parameters $a$ to $e$ for both IDT-to-RON and IDT-to-MON models can be seen in Table 5 and offer good agreement between the model predicted octane numbers and the experimentally calculated octane numbers, as seen in Figure 9, with the IDT-to-RON model having an $\mathrm{R}^{2}$ value of 0.9943 and the IDT-to-MON model having an $\mathrm{R}^{2}$ value of 0.9882 . Here it is necessary to note, that the models indicated by Table S2 in Supporting Information are different in detail to those proposed by Singh et al. The reason for this is due to slight differences in the ignition delay computed by the kinetic model constructed in this study, to those computed by the kinetic model of Singh et al. for the same mixture composition.

The ignition delay time for ethyl levulinate at a temperature of $750 \mathrm{~K}$, a pressure of 25 bar and equivalence ratio 1 is calculated to be $0.263 \mathrm{~s}$. Using the IDT-to-RON model derived in this study, the RON for ethyl levulinate is estimated to be 97.7. The ignition delay time for ethyl levulinate at a temperature of $825 \mathrm{~K}$, a pressure of 25 bar and equivalence ratio of 1 is calculated to be 0.0498 s. Using the IDT-to-MON model derived in this study, the MON for ethyl levulinate is estimated to be 93 . This analysis indicates that from a pre-vaporised kinetic stand point, ethyl levulinate is much more suitable as a spark ignition, gasoline type fuel than as a diesel fuel component, as has been suggested by previous studies.

From ignition quality tests, Tian et al. [14] found that ethyl levulinate had a superior antiknock quality than EURO 95 gasoline $(\mathrm{RON}=95)$ and iso-octane (RON 100). Thus, from their results one would expect ethyl levulinate to have a RON greater than 100 . The accuracy of predicted RON and MON values in this work are influenced by two factors, the uncertainty in the computed ignition delay time and it is also limited to the extremes of the RON and MON ranges studied by 
Singh et al. [36]. However, as the ignition delay times calculated are well within the asymptotic region of the RON/MON vs computed ignition delay time curve generated by Singh et al. the uncertainty in the ignition delay time is due to uncertainties in simulated ignition delay are negligible. In fact, even an assumed uncertainty in the simulated ignition delay time of $20 \%$ has no influence of the derived RON and MON values. Thus, the greatest uncertainty in the calculated RON and MON values originates from the limited range of fuels studied by Singh et al, i.e. $<100$ octane numbers. The estimates of ethyl levulinate octane numbers quoted above are therefore to be more accurately defined as $\mathrm{RON} \geq 97.7$ and $\mathrm{MON} \geq 93$.

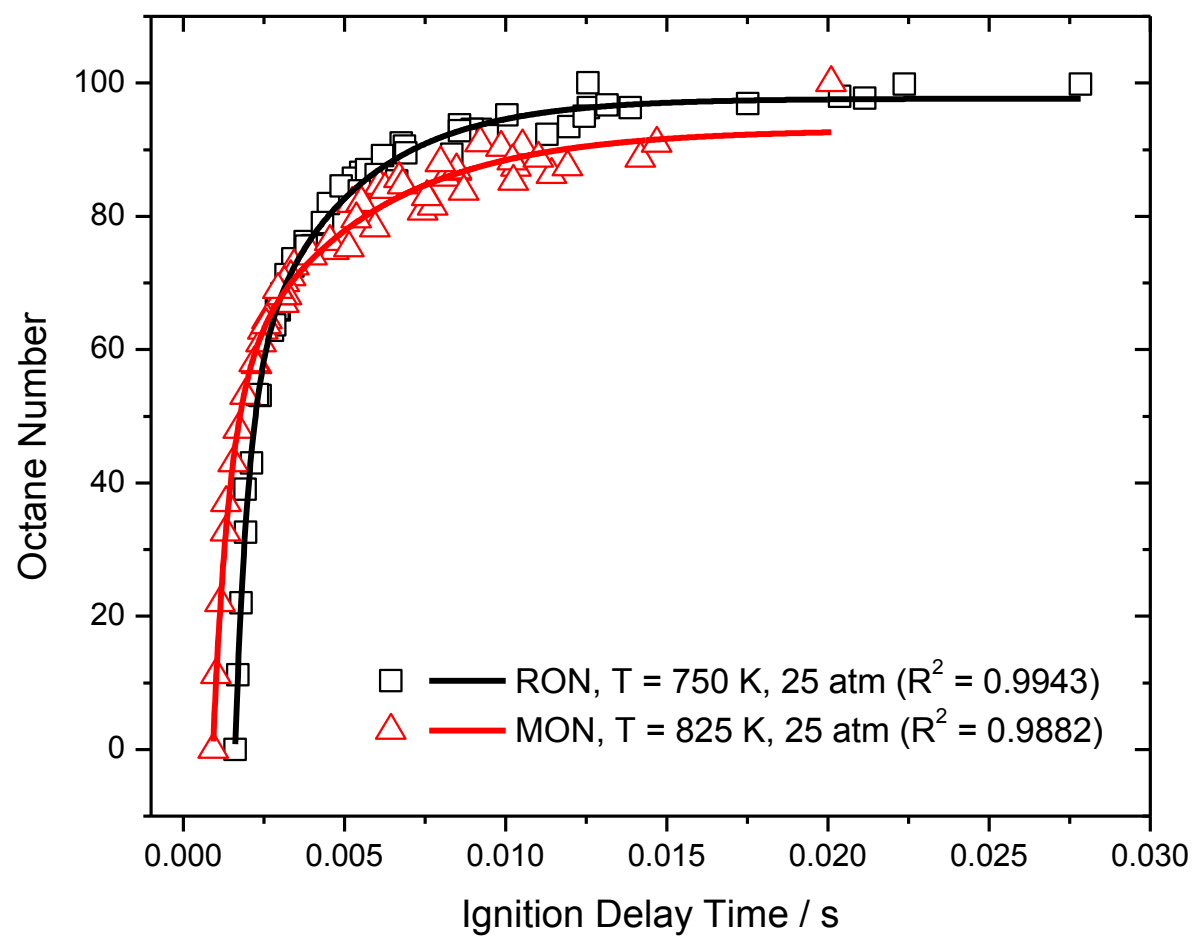

Figure 9. Measured Research (RON) and Motored Octane Numbers (MON) of Singh et al. [36] (symbols) vs calculated ignition delay times from this study (lines), for the reference fuels described in Table S2 (symbols). Ignition delay times were calculated at a pressure of 25 bar, an equivalence ratio of 1 and a temperature of $750 \mathrm{~K}$ and $825 \mathrm{~K}$ to represent the RON and MON conditions respectively.

\begin{tabular}{ccc}
\hline \multirow{2}{*}{ Parameter } & \multicolumn{2}{c}{ Model } \\
\cline { 2 - 3 } & "IDT to RON" & "IDT to MON" \\
\hline $\mathbf{A}$ & $9.77{\mathrm{X} 10^{+1}}^{+1}$ & $9.30 \times 10^{+1}$ \\
\hline
\end{tabular}




\begin{tabular}{ccc}
\hline B & $-2.58 \times 10^{+3}$ & $-3.24 \times 10^{+2}$ \\
$\mathbf{C}$ & $4.15 \times 10^{-4}$ & $5.05 \times 10^{-4}$ \\
$\mathbf{D}$ & $-7.31 \times 10^{+1}$ & $-5.03 \times 10^{+1}$ \\
$\mathbf{E}$ & $3.16 \times 10^{-3}$ & $4.17 \times 10^{-3}$ \\
\hline \hline
\end{tabular}

Table 5. Estimated model parameters for the IDT-to-RON and IDT-to-MON models.

\section{Conclusions}

The gas phase combustion kinetics of the proposed lignocellulosic biofuel, ethyl levulinate (EL), have been studied. Shock tube and rapid compression machine measured ignition delays show the molecule to exhibit a truncated range of reactivity, igniting at temperatures above $\sim 1040 \mathrm{~K}$ at 10 atm.

A detailed kinetic model for ethyl levulinate combustion is proposed substantially based on these calculations and stands ready to be used for the consideration of ethyl levulinate with gasoline reference fuels in combustion simulations. The model suggests that ethyl levulinate oxidation induction chemistry to be dominated by the ethyl ester, rather than the ketone, functionality of the fuel structure. As is characteristic of ethyl esters, ethyl levulinate predominantly decomposes to form an acid, in levulinic acid, and ethylene. Reacting flux and sensitivity analysis of the model show the oxidation chemistry of these species to dominate the temporal occurrence of ethyl levulinate ignition under the conditions tested. Calculations performed with the kinetic model estimate the RON and MON of ethyl levulinate to be $\geq 97.7$ and $\geq 93$, respectively. This suggests that ethyl levulinate would be best suited as a gasoline fuel component rather than a diesel fuel component as prevalent in the literature, indeed it may be considered to be useful as an octane booster.

\section{Acknowledgements}

Research (University of Limerick, Trinity College Dublin \& KAUST) reported in this publication was carried out under the Future Fuels project supported by the Competitive Center Funding (CCF) program at King Abdullah University of Science and Technology (KAUST). Research conducted at National University of Ireland, Galway and Trinity College Dublin was supported by Science 
Foundation Ireland. Computational resources were provided by the Irish Centre for High-End Computing, ICHEC.

\section{Supplementary Materials}

Supplementary material associated with this article can be found, in the online version, at doi:xxx.

\section{References}

[1] M. Mascal, E.B. Nikitin, High-yield conversion of plant biomass into the key value-added feedstocks 5-(hydroxymethyl)furfural, levulinic acid, and levulinic esters via 5(chloromethyl)furfural, Green Chemistry 12 (2010) 370-373.

[2] T. Flannelly, S. Dooley, J.J. Leahy, Reaction Pathway Analysis of Ethyl Levulinate and 5Ethoxymethylfurfural from d-Fructose Acid Hydrolysis in Ethanol, Energy \& Fuels 29 (2015) 75547565.

[3] M.K. Ghosh, S. Dooley, Accurate Thermochemistry for Oxygenate Hydrocarbons, A Case Study (In Preparation). Supplementary Materials Provided for Review.

[4] A.M. El-Nahas, M.V. Navarro, J.M. Simmie, J.W. Bozzelli, H.J. Curran, S. Dooley, W. Metcalfe, Enthalpies of Formation, Bond Dissociation Energies and Reaction Paths for the Decomposition of Model Biofuels: Ethyl Propanoate and Methyl Butanoate, The Journal of Physical Chemistry A 111 (2007) 3727-3739.

[5] J.M. Hudzik, J.W. Bozzelli, Thermochemistry and bond dissociation energies of ketones, J Phys Chem A 116 (2012) 5707-5722.

[6] T. Lei, Z. Wang, Y. Li, Z. Li, X. He, J. Zhu, Performance of a Diesel Engine with Ethyl Levulinate-Diesel Blends: A Study using Grey Relational Analysis, 2013.

[7] E. Koivisto, N. Ladommatos, M. Gold, Compression Ignition and Exhaust Gas Emissions of Fuel Molecules Which Can Be Produced from Lignocellulosic Biomass: Levulinates, Valeric Esters, and Ketones, Energy \& Fuels 29 (2015) 5875-5884. 
[8] B.C. Windom, T.M. Lovestead, M. Mascal, E.B. Nikitin, T.J. Bruno, Advanced distillation curve analysis on ethyl levulinate as a diesel fuel oxygenate and a hybrid biodiesel fuel, Energy \& Fuels 25 (2011) 1878-1890.

[9] M.J. Murphy, J.D. Taylor, R.L. McCormick, Compendium of experimental cetane number data, National Renewable Energy Laboratory, NREL/SR-540-36805, (2004).

[10] E. Christensen, A. Williams, S. Paul, S. Burton, R.L. McCormick, Properties and Performance of Levulinate Esters as Diesel Blend Components, Energy \& Fuels 25 (2011) 5422-5428.

[11] M.A. Lake, S.W. Burton, Diesel fuel compositions containing levulinate ester, Google Patents, 2010.

[12] H. Joshi, B.R. Moser, J. Toler, W.F. Smith, T. Walker, Ethyl levulinate: A potential bio-based diluent for biodiesel which improves cold flow properties, Biomass and bioenergy 35 (2011) 32623266.

[13] E. Christensen, J. Yanowitz, M. Ratcliff, R.L. McCormick, Renewable Oxygenate Blending Effects on Gasoline Properties, Energy \& Fuels 25 (2011) 4723-4733.

[14] M. Tian, R.L. McCormick, J. Luecke, E. de Jong, J.C. van der Waal, G.P.M. van Klink, M.D. Boot, Anti-knock quality of sugar derived levulinic esters and cyclic ethers, Fuel 202 (2017) 414-425. [15] J. Würmel, J.M. Simmie, CFD studies of a twin-piston rapid compression machine, Combustion and Flame 141 (2005) 417-430.

[16] A.S. AlRamadan, J. Badra, T. Javed, M. Al-Abbad, N. Bokhumseen, P. Gaillard, H. Babiker, A. Farooq, S.M. Sarathy, Mixed butanols addition to gasoline surrogates: Shock tube ignition delay time measurements and chemical kinetic modeling, Combustion and Flame 162 (2015) 3971-3979.

[17] K.P. Somers, J.M. Simmie, Benchmarking Compound Methods (CBS-QB3, CBS-APNO, G3, G4, W1BD) against the Active Thermochemical Tables: Formation Enthalpies of Radicals, The Journal of Physical Chemistry A 119 (2015) 8922-8933.

[18] J.M. Simmie, K.P. Somers, Benchmarking Compound Methods (CBS-QB3, CBS-APNO, G3, G4, W1BD) against the Active Thermochemical Tables: A Litmus Test for Cost-Effective Molecular Formation Enthalpies, The Journal of Physical Chemistry A 119 (2015) 7235-7246. 
[19] Z. Serinyel, N. Chaumeix, G. Black, J.M. Simmie, H.J. Curran, Experimental and Chemical Kinetic Modeling Study of 3-Pentanone Oxidation, The Journal of Physical Chemistry A 114 (2010) 12176-12186.

[20] W.K. Metcalfe, S. Dooley, H.J. Curran, J.M. Simmie, A.M. El-Nahas, M.V. Navarro, Experimental and Modeling Study of C5H10O2 Ethyl and Methyl Esters, The Journal of Physical Chemistry A 111 (2007) 4001-4014.

[21] W.K. Metcalfe, C. Togbé, P. Dagaut, H.J. Curran, J.M. Simmie, A jet-stirred reactor and kinetic modeling study of ethyl propanoate oxidation, Combustion and Flame 156 (2009) 250-260.

[22] E.R. Ritter, J.W. Bozzelli, THERM: Thermodynamic property estimation for gas phase radicals and molecules, International Journal of Chemical Kinetics 23 (1991) 767-778.

[23] H.J. Curran, P. Gaffuri, W.J. Pitz, C.K. Westbrook, A Comprehensive Modeling Study of nHeptane Oxidation, Combustion and Flame 114 (1998) 149-177.

[24] H.J. Curran, P. Gaffuri, W.J. Pitz, C.K. Westbrook, A comprehensive modeling study of isooctane oxidation, Combustion and Flame 129 (2002) 253-280.

[25] A.T. Blades, P.W. Gilderson, KINETICS OF THE THERMAL DECOMPOSITION OF ETHYL PROPIONATE, Can J Chem 38 (1960) 1412-1415.

[26] C.K. Westbrook, W.J. Pitz, P.R. Westmoreland, F.L. Dryer, M. Chaos, P. Osswald, K. KohseHöinghaus, T.A. Cool, J. Wang, B. Yang, N. Hansen, T. Kasper, A detailed chemical kinetic reaction mechanism for oxidation of four small alkyl esters in laminar premixed flames, Proceedings of the Combustion Institute 32 (2009) 221-228.

[27] A. Farooq, D.F. Davidson, R.K. Hanson, C.K. Westbrook, A comparative study of the chemical kinetics of methyl and ethyl propanoate, Fuel 134 (2014) 26-38.

[28] W. Ren, R. Mitchell Spearrin, D.F. Davidson, R.K. Hanson, Experimental and Modeling Study of the Thermal Decomposition of C3-C5 Ethyl Esters Behind Reflected Shock Waves, The Journal of Physical Chemistry A 118 (2014) 1785-1798.

[29] A. mech., http://www.nuigalway.ie/c3/aramco2/frontmatter.html. 
[30] J.P. Orme, H.J. Curran, J.M. Simmie, Experimental and Modeling Study of Methyl Cyclohexane Pyrolysis and Oxidation, The Journal of Physical Chemistry A 110 (2006) 114-131.

[31] S. Dooley, H.J. Curran, J.M. Simmie, Autoignition measurements and a validated kinetic model for the biodiesel surrogate, methyl butanoate, Combustion and Flame 153 (2008) 2-32.

[32] M. Chaos, A. Kazakov, Z. Zhao, F.L. Dryer, A high-temperature chemical kinetic model for primary reference fuels, International Journal of Chemical Kinetics 39 (2007) 399-414.

[33] M. Mehl, W.J. Pitz, C.K. Westbrook, H.J. Curran, Kinetic modeling of gasoline surrogate components and mixtures under engine conditions, Proceedings of the Combustion Institute 33 (2011) 193-200.

[34] S. Thion, A.M. Zaras, M. Szori, P. Dagaut, Theoretical kinetic study for methyl levulinate: oxidation by $\mathrm{OH}$ and $\mathrm{CH} 3$ radicals and further unimolecular decomposition pathways, Physical Chemistry Chemical Physics 17 (2015) 23384-23391.

[35] M. AlAbbad, B.R. Giri, M. Szőri, A. Farooq, On the high-temperature unimolecular decomposition of ethyl levulinate, Proceedings of the Combustion Institute 36 (2017) 187-193.

[36] E. Singh, J. Badra, M. Mehl, S.M. Sarathy, Chemical Kinetic Insights into the Octane Number and Octane Sensitivity of Gasoline Surrogate Mixtures, Energy \& Fuels 31 (2017) 1945-1960. 